\title{
O Brother, Where Art Thou? The Effects of Having a Sibling on Geographic Mobility and Labor Market Outcomes*
}

\author{
Helmut Rainer ${ }^{\dagger} \quad$ Thomas Siedler ${ }^{\ddagger}$
}

September 5, 2005

\begin{abstract}
In most industrialized countries, more people than ever are having to cope with the burden of caring for elderly parents. This paper formulates a model to explain how parental care responsibilities and family structure interact in affecting children's mobility characteristics. A key insight we obtain is that the mobility of young adults crucially depends on the presence of a sibling. Our explanation is mainly, but not exclusively, based on a sibling power effect. Siblings compete in location and employment decisions so as to direct parental care decisions at later stages towards their preferred outcome. Only children are not exposed to this kind of competition. This causes an equilibrium in which siblings not only exhibit higher mobility than only children, but also have better labor market outcomes. Using data from the German Socio-Economic Panel Study (SOEP) and from the American National Survey of Families and Households (NSFH), we find strong evidence that confirms these patterns. The implications of our results are then discussed in the context of current population trends in Europe and the United States.
\end{abstract}

Keywords: Geographic Mobility, Intergenerational Relationships, Care of the Elderly, Family Bargaining.

JEL Classifications: D62, J13, C14.

${ }^{*}$ We thank Michèle Belot, Venkataraman Bhaskar, John Ermisch, Marco Francesconi, Johannes Huinink, Stephen Jenkins, Paola Manzini, Stephen McKnight, Abhinay Muthoo, Markus Pannenberg, Steven Pudney, Mathis Schröder, Francis Vella, and participants at conferences and seminars at the 9th World Congress of the Econometric Society, European Economic Association's 20th Annual Congress, University of Essex (ISER), Berlin Network of Labor Market Economists, and SOEP Young Scholar Symposium for useful comments. All errors are our own.

${ }^{\dagger}$ School of Economics and Finance, University of St Andrews, St Salvator's College, St Andrews, KY16 9AL, United Kingdom. E-mail: hr11@st-andrews.ac.uk

${ }^{\ddagger}$ Institute for Social and Economic Research, University of Essex, Wivenhoe Park, CO4 3SQ, United Kingdom, and DIW Berlin. E-mail: tsiedl@essex.ac.uk. 
"Say you were an assistant bank manager, in Guildford. And you'd be thinking of emigrating, and then you were offered the job of managing a bank in Sydney. You might sit down with a bit of paper and draw up a list of pros and cons. You know:

CONS - aged parents, friends, golf club.

PROS - more money, better quality of life, sea, sunshine, etc.

It's no contest, is it?"

Nick Hornby, A Long Way Down, 2005

\section{INTRODUCTION}

Standard economic theory holds that geographic mobility plays a key role in the functioning of the market mechanism by ensuring a smooth transfer of labor out of contracting locations and into expanding ones. Yet, in practice, it is the lack of geographic mobility that is a recurrent source of concern - in particular in the European context. ${ }^{1}$ A commonly held view is that low geographic mobility can be attributed to a combination of high aggregate unemployment, intrinsic preferences against mobility and policy-induced distortions. ${ }^{2}$ But of all the factors said to affect geographic mobility, the one which has received little attention from economists are familial obligations such as adult children's caring for aged parents. Today, more adult children than ever before are having to cope with the burden of caring for elderly parents. Such caregiving is time consuming, taking an average of 20 hours per week (National Alliance for Caregiving [2004]), and geographic proximity between the caregiver and the care recipient is a key factor that helps the caregiver cope with elder care responsibilities (Stern [1995]). Against this background, this paper investigates how parental care responsibilities and family structure interact in affecting adult children's mobility patterns.

Imagine you are a young adult living in the same home or locality as your parents. After having finished your general education, a choice you may have to consider is a residential move in order to get a job in a distant labor market where the potential for increased life-time earnings exists. There are, however, costs associated with the decision to move that must be weighed against the expected gains. A residential move may cause problems in the future for those social relationships that require face to face contact: in particular, you may have to adjust future time allocations to meet the social and physical needs of your aged parents. What determines the propensity that you will eventually move away from your home region?

\footnotetext{
${ }^{1}$ Indeed, many people in Europe do not move very far over their lifespan. For example, in the United Kingdom approximately 44 percent of the population live within the local authority in which they were born (Gregg et al. [2004]). The lack of mobility is particularly notable in Germany, where approximately 59 percent of the population live in the town of their childhood. We have used SOEP data from 2002 to compute this figures.

${ }^{2}$ These last include in particular centralized wage agreements (Tatsiramos [2004], Braunerhjelm et al. [2000]), high unemployment benefits (Antolin and Bover [1997], Bertola [1999], Nickell and Layard [1999]) and regional housing policies (Oswald [1997]).
} 
We start with the idea that family-related factors might affect the mobility pattern of young adults through three different channels. First, parental characteristics such as age affect mobility: the more likely it is that a parent needs a substantial amount of attention or care in the near future, the lower the probability that a young adult moves out of the home region. ${ }^{3}$ Second, the presence of an alternative potential caregiver such as a sibling affects mobility: only children, unlike siblings, make decisions unaffected by various externalities that siblings introduce into each other's environment. Third, the probability that a given young adult becomes a mover is higher if that person grows up in a region with low employment prospects.

In this paper we address these ideas both theoretically and empirically. Our theoretical model consists of a two-period game in which the players are two adult siblings. In the first period, the children decide non-cooperatively on where to live and where to seek employment. In the second period, as parents age or experience declines in health, they require attention and care. These life cycle events place demands upon their children. We model the impact of family caregiving on adult children in the context of a model that recognizes not only several competing uses of time, but also the possibility of strategic interactions among adult siblings when making care decisions. The "caregiving game" which is the focus of our analysis captures a process of bargaining through which adult siblings take turns offering more or less help according to their parents' shifting needs and their variable ability to offer such support.

Our analysis shows several interesting results. As a benchmark, we first characterize the location and employment decisions of an only child conditional on his or her long-term family caregiving responsibilities. We then analyze the process of bargaining through which siblings try to figure out ways of sharing the responsibility for their parents. Bargaining power is inextricably bound up in this process. We show that a caregiving equilibrium exists in which the balance of power is on the side of the child who has "economic status". More precisely, the child who has a higher wage income and lives further away from the parents has a bargaining power advantage, and hence provides a smaller share of the required amount of care. Finally, we turn our attention to the siblings' equilibrium location decisions. A key insight we obtain is that the location choices of siblings interact with family care decisions at later stages so as to cause an equilibrium in which siblings systematically exhibit higher rates of mobility than only children: they are more likely to become movers if a potential for increased earnings opportunities outside the parents' location exists.

Our analysis shows that the intuition for this result can be decomposed into two effects: a sibling power effect and a resource constraint effect. The sibling power effect comes from

\footnotetext{
${ }^{3}$ There exists a strong gerontological basis for this hypothesis. For example, a 30 year old child with a 50 year old parent faces a 23 percent risk that the parent will fall victim to long-term illness within the next 5 years. In contrast, a 30 year old child with a 60 year old parent is exposed to a 39 percent risk that the parent suffers from a long-term illness within the next 5 years. These numbers are based on a healthy life expectancy study for Scotland (Clark et al. [2004], p. 45).
} 
noting that the traditional determinants of status in society - wage, income, or occupational status - place adult siblings in a stronger position to direct care decisions within the family towards their preferred outcome. This, in turn, translates into incentives for both siblings to move to where high-valued employments are. In fact, it is as if siblings compete in location and employment decisions so as to affect "who's got the say" in family care decisions at later stages. Hence the power structure between adult siblings has a determinate effect on their mobility pattern.

The explanation for the resource constraint effect is as follows. The fact that siblings may actually negotiate ways of sharing the responsibility for the care of their parents implies that any given sibling spends less time helping the parents than an only child, at least at the margin. The equilibrium location and employment decisions of adult siblings subsume this positive externality in a rational manner: anticipating lower parental care costs associated with a residential move, siblings are more likely to respond to better earnings opportunities outside the parents' home location by becoming movers.

We test our predictions using data from the German Socio-Economic Panel Study (SOEP) and the American National Survey of Families and Households (NSFH). Children with a sibling exhibit statistically significant higher rates of geographical mobility than only children. Consistent with our model, this pattern is especially prevalent in regions with low employment prospects. We demonstrate that these results are driven by the mechanisms highlighted in the theoretical model. We also find strong support for the hypothesis that, due to higher mobility, children with a sibling have better labor market outcomes. For example, siblings who grow up in economically deprived regions have around 10 percent higher labor earnings than only children from economically comparable regions. Similarly, siblings have a 10 percent higher chance of being in full-time employment and are less likely to be unemployed and economically inactive.

The paper proceeds as follows. Section 2 discusses the related literature. Section 3 lays down our theoretical model. Section 4 characterizes the location and employment decisions of an only child. Section 5 derives the main results concerning the mobility pattern of siblings. Section 6 describes the data and confronts the theoretical results with empirical evidence. Section 7 discusses the implications of our findings in the context of current population trends in Europe and the United States. Section 8 presents conclusions. All technical proofs are in the Appendix.

\section{Related Literature.}

The approach presented in this paper builds on two important microeconomic perspectives: (1) that adult children make decisions relative to parental care responsibilities long before the actual care is needed (Stern [1995]); and (2) that strategic interactions between siblings have a determinate effect on their mobility pattern (Konrad et al. [2002]).

Konrad et al. [2002] have recently developed a very interesting model that seeks an 
understanding of the mobility pattern of siblings in terms of a birth order effect. They argue that in families with two children, location choice has a strategic commitment value if it is made before actual caregiving occurs. In particular, they show that firstborn children may strategically choose to locate in some distance from their parents, essentially forcing second born children into staying closer to the parents and providing all of the caregiving in the future. The authors also report empirical evidence that suggests that firstborn siblings locate further away from their parents than second born siblings and only children.

From our point of view, the birth order effect highlighted in Konrad et al. [2002] is just one among many strategic elements that siblings introduce into each other's environment. This paper seeks an understanding of siblings in terms of power relationships, rather than in terms of birth order effects. We use the term "power relationship" to refer to the influence and relative bargaining power each sibling has within the family. The emphasis of this study is on the association between siblings' location and employment decisions and their subsequent ability to control decision-making within the family. Our main message is that the strategic influence of siblings on one another is more important that than the strategic influence of firstborn on second born siblings. In other words, the very presence of a sibling matters a lot more than birth order.

Stern [1995] also considers family decision-making in the context of a two-stage game. In the first stage, prior to the parents needing care, each family member makes decisions such as where to live, where to work, and whether to marry. In the second stage, the family jointly chooses a care arrangement. Stern [1995] addresses the fundamental question of whether or not family members act strategically in the first stage. In doing so, he provides some evidence that supports the hypothesis that family members take into account how first stage decisions affect second stage outcomes. Our empirical analysis considerably strengthens this evidence that young adults make decisions relative to long-term care decisions long before the actual care is needed.

\section{THe MOdel}

3.1. The Environment. We envision an environment in which a "linear economy" of length $\Delta \equiv \bar{x}-\underline{x}$ lies on the abscissa of a line. The economy is populated by a family that consists of parents $p$ and two children: child $f$ who is born first, and child $s$ who is born second. Parents $p$ are located at one extreme of the economy. More precisely, they live and raise their children at $x=\underline{x}$. There are two labor markets which are located at the extremes of the economy: a local labor market is situated at $x=\underline{x}$, while a distant labor market is at $x=\bar{x}$. Our model consists of a two period situation.

- Period 1: The "Location" Game. When $f$ and $s$ are young adults, they noncooperatively decide on where to live and where to seek employment. The former decision will be referred to as a location choice, while the latter will be referred to as an employment choice. We assume that child $f$ makes her employment and location choice first, which should be 
true in practice because she is older (Konrad et al. [2002]). The location choices are points $l_{f} \in[\underline{x}, \bar{x}]$ and $l_{s} \in[\underline{x}, \bar{x}]$. The employment choices are binary actions $e_{f} \in\{\underline{x}, \bar{x}\}$ and $e_{s} \in\{\underline{x}, \bar{x}\}$. We interpret the action $e_{i}=\underline{x}$ as $i$ 's $(i=f, s)$ decision to become employed in the local labor market, while the action $e_{i}=\bar{x}$ should be thought of as $i$ 's decision to become employed in the distant labor market. A benefit function $w_{i}: e_{i} \rightarrow \mathbb{R}$ represents the impact of the employment choice on future earnings potentials:

Assumption 1 (Opportunities at different job locations) For each $i \in\{f, s\}$, let

$$
w_{i} \equiv\left\{\begin{array}{lll}
\underline{w} & \text { if } & e_{i}=\underline{x} \\
\bar{w} & \text { if } & e_{i}=\bar{x}
\end{array}\right.
$$

where $\bar{w} \geq \underline{w}$.

Our basic notion here is that job prospects and earning opportunities in the distant labor market may be better than in the parents' home location. For example, unemployment rates in the local labor market may be high and jobs may be more unstable due to declining industries in the region.

One would expect that low earnings prospects in the home region should increase the net benefits of moving and push individuals away to higher-valued employments. But various factors besides the expected earnings differential influence the decision to become a mover. These determinants of geographic mobility include in particular the family background.

- Period 2: The "Caregiving Game". As parents retire and their social circle of friends and relatives begins to shrink, children become socially more important to them. Common events at this point of the parents' life cycle (such as the loss of a spouse, a long-standing illness or a disability) further heightens the elderly's dependence. It is well understood that adult children respond to the circumstances and shifting needs of their parents. For example, having a parent in poor health typically leads to a significant increase in time inputs of adult children devoted to parents. We now turn to an assumption which is intended to capture these issues.

At the beginning of period 2, a state of nature - referred to as parental needs status $k$ - is realized that determines the amount of care (or assistance) that parents require. The state of parental needs is assumed to be binary, either high $(k=h)$ with $\operatorname{Pr}(k=h)=\rho$ or low $(k=l)$ with $\operatorname{Pr}(k=l)=1-\rho$. We adopt the convention to refer to the state $k=h$ as "parental dependency" and to the state $k=l$ as "parental independency". Accordingly, $\operatorname{Pr}(k=h)=\rho$ will be sometimes referred to as a measure of expected parental dependency. The term "parental dependency" is to be understood in a wide sense. It refers to family circumstances such as the death of one parent or a close relative, parental divorce, or a limiting long-standing illness or disability. The difference between the two states is best captured in the distinction between "caring for" and "caring about" a family member. 
Assumption 2 ("Caring for" parents) Let $g^{h}$ denote the amount of care visits that parents require in the realization $k=h$. If the siblings reach an agreement on how to provide the required amount of care, each child $i(i=f, s)$ derives utility $G^{h}$ from the fact that parental needs are satisfied.

We would like to elaborate on this. The need for care and assistance by parents may generate interesting interactions among adult siblings, as they might seek ways of jointly providing the required support to their parents. ${ }^{4,5}$ Indeed, sociologists have long emphasized that it is common for siblings to engage in a process of bargaining through which they take turns offering more or less help according to shifting needs of parents and their variable ability to offer. The bargaining game which will be the focus of our analysis captures a situation in which a fixed number of care units $g^{h}$ is required to meet the parents' requirements of the situation, and player $f$ and player $s$ propose to respectively contribute $s_{f}^{h}$ and $s_{s}^{h}$ care units to the required amount of care. ${ }^{6}$ The precise structure of the bargaining protocol will be specified in later sections.

The above assumption concerns the state of parental dependency which involves a public good game between those implicated in providing eldercare. What about ties between parents and children in the state of parental independency? With the parents' capacity to deal with self-care intact, caregiving is no longer motivated by parental needs. However, each child will privately need to put in a positive (but potentially small) amount of effort to maintain a valuable parent-child relationship.

Assumption 3 ("Caring about" parents) Let $g^{l}$ denote the minimum number of face-toface contacts each child $i(i=f, s)$ is required to make to derive private benefits $G^{l}$ from the parent-child relationship in the realization $k=l$.

With these preliminaries in hand, we now turn to the payoff consequences of parent-care.

3.2. Assumptions on the Payoff Consequences of Parent-Care. Empirical research has shown that adult children appear to respond to the circumstances of their parents, and that the form of response is strongly influenced by economic considerations, particularly the opportunity cost of time, as measured by the market wage rate (Couch et al. [1999]). Moreover, it is well understood that working-age adults may support their parents by reducing work hours, using vacation and sick days for parent care, giving up opportunities for job advancement or forfeiting leisure time. These findings suggest to investigate the

\footnotetext{
${ }^{4}$ Note that we only consider time inputs provided to elderly parents and not monetary transfers from adult children to their parents. This is a realistic scenario. Szydlik [2000] reports that in Germany less than 4 percent of children aged between 40-85 years make financial transfers to their parents in a given year.

${ }^{5}$ The caregiving assistance that is required may involve help with instrumental activities of daily living (such as managing medications, transporting the elder to various appointments, shopping, or housekeeping) and help with activities of daily living (such as bathing, dressing or eating).

${ }^{6}$ Pezzin et al. [2003], Engers and Stern [2002] and Pezzin and Schone [1999] also examine care decisions using game-theoretic models of family bargaining.
} 
impacts of parent care in the context of a model that not only allows for strategic interactions among adult siblings when making family care decisions, but also recognizes two theoretically competing uses of time, namely time spent working in the labor market and time spent providing care for potentially noncoresident elderly parents. ${ }^{7}$

Consider a model of time allocation in which each sibling has an exogenously given time endowment $m$. Suppose that, in period 1 , the siblings make an arbitrary pair of location decisions $\left(l_{f}, l_{s}\right)$, and an arbitrary pair of employment decision $\left(e_{f}, e_{s}\right)$. And furthermore, consider an arbitrary state $k \in\{h, l\}$ that our game form admits in the second period. If child $i$ provides $s_{i}^{k}$ care units, then $i$ 's $(i=f, s)$ fixed time budget $m$ is allocated among three time uses: paid market work $h_{i}^{k}$, time spent caring for parents $s_{i}^{k}$, and commuting time:

$$
m=h_{i}^{k}\left(1+\delta_{i}^{e}\right)+s_{i}^{k}\left(1+\delta_{i}^{p}\right)
$$

The time cost per care visit $s_{i}^{k}$ is made up of one unit of time actually spent providing care plus travel time that, by appropriate normalization, is equal to the actual distance

$$
\delta_{i}^{p}=\left|l_{i}-\underline{x}\right|
$$

between child $i$ 's chosen place of residence $l_{i}$ and the parents' location. Similarly, the time cost per labor market unit is made up of one unit of time actually spent working plus commuting time that is equal to the actual distance

$$
\delta_{i}^{e}=\left|l_{i}-e_{i}\right|
$$

between $i$ 's chosen place of residence $l_{i}$ and $i$ 's chosen job location $e_{i}$.

Market work $h_{i}^{k}$ earns child $i$ an income $w_{i} h_{i}^{k}$ which is assumed to be entirely spent on private consumption $c_{i}$. Recall that child $i$ 's wage rate $w_{i}$ is endogenously determined by her employment choice $e_{i}$ in period 1 (see Assumption 1). We shall assume that the second-period utility for child $i$ takes the linear form

$$
\begin{gathered}
u_{i}^{k}=c_{i}\left(s_{i}^{k}\right)+G^{k}, \quad \text { where } \\
c_{i}\left(s_{i}^{k}\right)=w_{i}\left[m-s_{i}^{k}\left(1+\delta_{i}^{p}\right)\right] /\left(1+\delta_{i}^{e}\right) .
\end{gathered}
$$

The equilibrium of our game has two key components. The first is the caregiving game between adult siblings. The second is the equilibrium in the location game. It is assumed that the two-stage game is one with complete information. Before proceeding to the study

\footnotetext{
${ }^{7}$ Of course, in reality, time spent working in the labor market and time spent providing care should not be considered in isolation. Our results would be analogous, but slightly more complicated, if we were to decompose the second period into a step where siblings negotiate caregiving shares and then each child makes leisure and work decisions conditional on the care decision. Thus our approach should be viewed as a "reduced form" of a model in which market time, time spent providing care and leisure time are jointly determined.
} 
of the subgame-perfect equilibrium of our model, we investigate the model with an only child, denoted $o$, who does not have a sibling to participate in the caregiving game.

\section{An Only Child}

Only children represent a kind of "controlled experiment" - what it is like to grow up and make decisions unaffected by the externalities that siblings introduce into each other's environments. The analysis of the optimal actions of an only child is straightforward. Assume that the underlying parameters are such that $c_{o}\left(g^{k}\right)+G^{k}>c_{o}(0)$ for all $k \in$ $\{l, h\}$; for otherwise gains from providing the required amount of care do not exist. Given that gains from parental care exist, period 2 of the game is mechanical: child $o$ is the sole caregiver "de facto", and provides $g^{k}$ care units in each state $k$ (where $k=l$ or $k=h$ ). Accordingly, child $o$ 's time budget is allocated between labor market units $h_{o}$ that yield private consumption $c_{o}\left(\equiv w_{o} h_{o}\right)$ and family care units $g^{k}$ in such a way that $m=h_{o}\left(1+\delta_{o}^{e}\right)+g^{k}\left(1+\delta_{o}^{p}\right)$ for given distances $\delta_{o}^{e}$ and $\delta_{o}^{p}$ (which are defined above in (2) and (3)). It follows that the end-of-period payoff to child $o$ in each state $k(k=l, h)$ will be as in (4) and (5), but with $s_{i}^{k}$ replaced by $g^{k}$.

In period 1 , child $o$ maximizes expected utility by a location choice of $l_{o} \in[\underline{x}, \bar{x}]$ and an employment choice of $e_{o} \in\{\underline{x}, \bar{x}\} .{ }^{8}$ Both the earnings differential between the origin and destination area, $\omega \equiv \bar{w} / \underline{w}$, and the degree of parental dependency, $\rho$, are key to the analysis of the optimal employment and location decision of an only child (see Figure 1):

RESUlt 1 (The Equilibrium Location of an Only Child) Given the above specifications, the following results are obtained. In Regions $A(1)$ and $A(2)$, the optimal actions of child $s$ are to live and to seek employment in her home region at $\underline{x}$. In Region A(3), the optimal action of child $s$ is to move in order to live and seek employment in the destination area at $\bar{x}$. In Region $A(4)$, the optimal actions of child s are to live at her home region $\underline{x}$ and to work in the destination area at $\bar{x}$. The definitions of the regions are as follows:

$$
\begin{gathered}
A(1)=\{(\omega, \rho) \in[1, \infty) \times[0,1] \mid \omega \leq \hat{\omega} \quad \text { and } \rho \leq \hat{\rho}\} \\
A(2)=\{(\omega, \rho) \in[1, \infty) \times[0,1] \mid \omega \leq 1+\Delta \quad \text { and } \rho>\hat{\rho}\} \\
A(3)=\{(\omega, \rho) \in[1, \infty) \times[0,1] \mid \omega>\hat{\omega} \text { and } \rho<\hat{\rho}\} \\
A(4)=\{(\omega, \rho) \in[1, \infty) \times[0,1] \mid \omega>1+\Delta \text { and } \rho \geq \hat{\rho}\}
\end{gathered}
$$

where

$$
\hat{\omega} \equiv \frac{\left(m-g^{l}\right)-\rho\left(g^{h}-g^{l}\right)}{m-(1+\Delta)\left[g^{l}+\rho\left(g^{h}-g^{l}\right)\right]} \quad \text { and } \quad \hat{\rho} \equiv \frac{m-g^{l}(2+\Delta)}{\left(g^{h}-g^{l}\right)(2+\Delta)} .
$$

\footnotetext{
${ }^{8}$ In the Appendix it is shown that although any location in the interval $[\underline{x}, \bar{x}]$ is possible, child $o$ will optimally locate at one extreme of the economy, that is, either at $\underline{x}$ or at $\bar{x}$. It thus follows that the equilibrium decisions of an only child are based on comparing four states of the world, namely $l_{o}=\underline{x}$ or $l_{o}=\bar{x}$ combined with $e_{o}=\underline{x}$ or $e_{o}=\bar{x}$.
} 
Residential and job mobility can take three patterns. The first is that in which both residence and employment are sought in the home region [regions $A(1)$ and $A(2)$ ]. There can be two reasons for this type of outcome. The first is that a relatively low level of the earnings differential $\bar{w} / \underline{w}$ between the two labor market regions may induce a person not to move, even in the presence of a low level of parental dependency as captured by a low value of $\rho$ [region $A(1)]$. The second reason for this type of outcome is that a high level parental dependency may induce a person not to move, even when the earnings differential between the origin and destination area is at relatively high (medium-valued) level [region $A(2)$ ]. The second observed pattern of mobility is that of job mobility accompanied by residential mobility [region $A(3)$ ]. This type of mobility arises in response to relatively large earnings differentials between the origin and destination area, and a low level of parental dependency. Finally, the third type of mobility is that of job mobility, but residential attachment to the home region [region $A(4)$ ]. This type of mobility exists because of a relatively high level of parental dependency, which speaks in favor of living close to the parents' place of residence. On the other hand, the high wage differential between home and distant area speaks in favor of working in the distant labor market and plays the role of compensating $s$ for the incurred commuting costs.

To summarize, since long-term care needs are taken into account prior to the parents actually needing care, a child will not necessarily become a mover in all situations where a potential for increased earning opportunities outside the parents' origin location exists. Furthermore, the more likely it is that a parent needs a substantial amount of care in the near future, the lower the probability that an only child moves out of the home region. The mobility pattern of siblings may have several different dimensions, as we will show next.

\section{SiBLingS}

5.1. Bargaining Equilibrium in the "Caregiving" Game In order to describe the bargaining process (when $k=h$ ) in a simplified manner, we now assume that the bargaining process is such that the equilibrium negotiated caregiving shares $s_{f}^{h}$ and $s_{s}^{h}$ can be characterized by the Nash bargaining solution (NBS, for short) in which the disagreement point is given by

$$
d_{f}^{h}=c_{f}(0) \quad \text { and } \quad d_{s}^{h}=c_{s}(0),
$$

where $c_{i}(0)(i=f, s)$ is as in $(5)$, but with $s_{i}^{h}=0$. It may be noted that the payoffs encapsulated in $d_{f}^{h}$ and $d_{s}^{h}$ represent the impasse point in which $f$ and $s$ perpetually disagree over how to share the required amount of parental care. ${ }^{9}$ The Nash bargaining solution of

\footnotetext{
${ }^{9}$ The way we apply Nash's bargaining solution is informed by non-cooperative bargaining theory. In fact the NBS of our bargaining problem is identical to the limiting equilibrium outcome of Rubinstein's (1982) alternating-offers bargaining game in which both players have inside options, and can also be derived in the context of the "subscription game" analyzed by Admati and Perry (1991). For a thorough discussion of the strategic foundations of the NBS see Muthoo (1999).
} 
the bargaining situation described above is the unique pair of caregiving shares, denoted $\left(\hat{s}_{f}^{h}, \hat{s}_{s}^{h}\right)$, that solves the following maximization problem:

$$
\max _{s_{f}^{h}, s_{s}^{h}}\left[c_{f}\left(s_{f}^{h}\right)+G-c_{f}(0)\right]\left[c_{s}\left(s_{s}^{h}\right)+G-c_{s}(0)\right]
$$

subject to $0 \leq s_{f}^{h} \leq g^{h}$ and $s_{s}^{h}=g^{h}-s_{f}^{h}$. The following proposition states the main result of this section, which describes the equilibrium caregiving shares provided by $f$ and $s$ :

RESult 2 (Bargaining Equilibrium) Consider the "caregiving game" in period 2, and fix arbitrary actions $\left(l_{f}, e_{f}\right)$ and $\left(l_{s}, e_{s}\right)$ chosen in period 1 . For each $i, j \in\{f, s\}$, define:

$$
\theta_{i} \equiv\left[\frac{G\left(1+\delta_{i}^{e}\right)}{w_{i}\left(1+\delta_{i}^{p}\right)}\right]
$$

Then the equilibrium negotiated caregiving shares provided by $f$ and $s$ respectively are given by

$$
\hat{s}_{f}^{h}=\frac{g^{h}+\theta_{f}-\theta_{s}}{2} \quad \text { and } \quad \hat{s}_{s}^{h}=\frac{g^{h}-\theta_{f}+\theta_{s}}{2} \quad .
$$

As expected, the sum of the Nash-bargained caregiving shares equals the required amount of care. Notice that $i$ 's $(i=f, s)$ caregiving share $\hat{s}_{i}^{h}$ is strictly increasing in $\theta_{i}$ and strictly decreasing in $\theta_{j}$. Thus $\theta_{i}$ represents the inverse of $i$ 's bargaining power, while $\theta_{j}$ is the inverse of $j$ 's bargaining power. A key and rather interesting feature of our caregiving game is that the siblings' bargaining powers are endogenously determined and depend crucially on first-period actions as captured in the expressions $\theta_{f}$ and $\theta_{s}$. Hence the equilibrium caregiving shares $\hat{s}_{f}^{h}$ and $\hat{s}_{s}^{h}$ are systematically pegged to the players' value of time (as captured by their wage rates $w_{f}$ and $w_{s}$ ) and the locations of the players relative to that of their parents (as captured by $\delta_{f}^{p}$ and $\delta_{s}^{p}$ ). It is particularly interesting to note that the present result reconciles much of the empirical literature on family care decisions.

First, notice that for any arbitrary $w_{i}^{1}$ and $w_{i}^{2}$ such that $w_{i}^{1}>w_{i}^{2}$, it is the case that $\hat{s}_{i}^{h}\left(w_{i}^{1}\right)<\hat{s}_{i}^{h}\left(w_{i}^{2}\right)$ and $\hat{s}_{j}^{h}\left(w_{i}^{1}\right)>\hat{s}_{j}^{h}\left(w_{i}^{2}\right)$ for $i, j=f, s$ and $i \neq j$. That is, a (marginal) increase in child $i$ 's wage rate decreases $i$ 's share of the caregiving and increases child $j$ 's share of the caregiving. This suggests that adult siblings with higher wage rates are predisposed to spent less time providing care for older generations. This finding can readily be interpreted using price-of-time arguments. As wage rates rise, time transfers become more costly, and the negotiated caregiving arrangement will reflect the relative cost of parental care of the parties involved. Empirical studies which provide evidence that supports this result include Sloan et al. [1997], Couch et al. [1999], and Ermisch [2004].

Second, also note that for arbitrary distances $\delta_{i}^{p 1}$ and $\delta_{i}^{p 2}$ such that $\delta_{i}^{p 1}>\delta_{i}^{p 2}$, we have that $\hat{s}_{i}^{h}\left(\delta_{i}^{p 1}\right)<\hat{s}_{i}^{h}\left(\delta_{i}^{p 2}\right)$ and $\hat{s}_{j}^{h}\left(\delta_{i}^{p 1}\right)>\hat{s}_{j}^{h}\left(\delta_{i}^{p 2}\right)$ for $i, j=f, s$ and $i \neq j$. That is, an increase in the distance between child $i$ 's place of residence and parents $p$ 's place of residence decreases $i$ 's share of the caregiving and increases child $j$ 's share of the caregiving. A basic 
notion captured here is that adult siblings offer more or less care assistance according to their relative ability to offer such support which depends on a child's location relative to that of her parents. These finding is consistent with empirical evidence that children who live close to the parents are perceived by other family members to be able to provide a lion share of parental care (see, for example, Stern [1995]; Stern [1996]; Engers and Stern [2002]; Ermisch [2004]).

5.2. Equilibrium in the Location Game. Continuing the backward induction, the next step would be to characterize $f$ and $s$ 's employment and location choices in period 1 . We postpone this, however, to emphasize that the present framework points immediately to a sharp distinction between the optimal actions of an only child and that of siblings. Indeed our framework offers three channels through which the mobility pattern of siblings may systematically differ from that of only children. We now discuss these three channels.

- Sibling Power Effect. With the players' bargaining powers $\theta_{f}$ and $\theta_{s}$ (and hence caregiving shares $s_{f}^{h}$ and $s_{s}^{h}$ ) in period 2 being determined endogenously according to geographic distance and economic status (wage income), rational individuals take into account how their location and employment decisions impact — via the bargaining process — the family decisions about care in the second period. If $f$ and $s$ recognize this dependence of ex-post bargaining powers on ex-ante decisions, then they may use their location and employment choices for purposes of maximizing their bargaining powers rather than simply to maximize their expected payoffs. In fact, it is as if siblings compete in location and employment decisions so as to influence "who's got the say" in family care decisions at latter stages.

- Resource Constraint Effect. The second channel that we highlight is the fact that in families with (at least) two children, care provision may be a responsibility shared across siblings. The ability of working-age adult siblings to figure out ways of sharing responsibility for their parents can be viewed as a "softening" of the demands placed upon their long-term resource constraints. Indeed, the very existence of an alternative family caregiver helps adult children to better strike a balance between activities that yield private consumption and family responsibilities. Of course, this positive externality is absent for only children. Conversely, the equilibrium strategies adopted by $f$ and $s$ at any equilibrium of the location game will subsume this externality in a rational manner.

- Birth-Order Effect. In the context of our model, birth order can be an important factor in the choice of sibling strategies. To see this, recall that we assume that the older child makes her location and employment decisions first, with the younger child moving second. It is well understood that, in such an environment, the first-mover can influence the decisions of the second-mover (see Konrad et al. [2002]). Hence, in addition to the previous two effects, birth order might also influence the outcome of the location game.

We can now summarize the above discussion in the following result, which compares the mobility decisions of adult siblings with that of only children (see Figure 2). 
RESUlt 3 (Siblings v/s Only Children.) There is a set of parameter values, condition $(C)$ in the Appendix, for which the following results are obtained. In Region B(1), both a child with a sibling and an only child would choose to live and seek employment in her home region. In Region B(4), both a child with a sibling and and only child would choose to live and seek employment in the distant labor market. In Region B(3), a child with a sibling would choose to live and be employed in the distant labor market, while an only child would choose to stay in her home region. Finally, in Region B(2), a child with a younger sibling decides to work and live outside her home region, while a child with an elder sibling and an only child stays in the same locality as her parents. The definitions of the regions are as follows:

$$
\begin{gathered}
B(1)=\{\omega \in[1, \infty) \mid \omega \leq \check{\omega}\} \\
B(2)=\{\omega \in[1, \infty) \mid \check{\omega}<\omega \leq \tilde{\omega}\} \\
B(3)=\{\omega \in[1, \infty) \mid \tilde{\omega}<\omega \leq \hat{\omega}\} \\
B(4)=\{\omega \in[1, \infty) \mid \omega>\hat{\omega}\}
\end{gathered}
$$

where

$$
\check{\omega} \equiv \frac{2\left(m-g^{l}\right)-\rho\left(g^{h}-2 g^{l}\right)}{2\left[m-(1-\rho) g^{l}(1+\Delta)\right]} \quad \text { and } \quad \tilde{\omega} \equiv \frac{2\left[\left(m-g^{l}\right)-\rho\left(g^{h}-g^{l}\right)\right]}{2 m-(1+\Delta)\left[2 g^{l}+\rho\left(g^{h}-2 g^{l}\right)\right]},
$$

and where $\hat{\omega}$ is defined in (7).

The above result uncovers a close connection between the mobility pattern of young adults and the following three factors: parental characteristics such as age that measure the degree of parental dependency in the near future; the presence of a sibling; and the economic circumstances and prospects in the region in which parents live. We now outline, in more specific terms, the empirical predictions based on the above result.

Our basic insight is that children with a sibling differ systematically from only children in their mobility pattern. Indeed the set of parameter values under which adult siblings would decide to become movers when a potential for increased earnings opportunities outside their parents' locality exists [Regions $B(3)$ and $B(4)]$ is strictly larger than the set of parameter values under which only children would move [Region $B(4)$ ]. In a large population, we would therefore expect to find that children with a sibling are on average located further away from their parents than only children. For future reference, we record our first observation as follows:

PREDiction 1 Siblings are more likely than only children to respond to low economic prospects in their home region by locating away from their parents. ${ }^{10}$

\footnotetext{
${ }^{10}$ While siblings are more likely to become movers than only children irrespective of birth order, our model also demonstrates that firstborn siblings may exhibit yet higher propensities to move than second
} 
It is well established that geographic mobility is a highly significant explanatory variable for a person's labor market outcomes. Our next prediction therefore refers to the effect of adult children's mobility patterns on labor market outcomes.

PrEDiction 2 Due to a higher propensity to locate away from their parents, adult siblings from areas with high unemployment rates or rural regions have on average (a) higher labor earnings, (b) a lower risk of unemployment, (c) higher full-time employment rates and (d) lower rates of economic inactivity than only children from economically comparable regions.

Our predictions, so far, suggest that siblings not only exhibit higher rates of mobility than only children, but as a consequence also have better labor market outcomes. What drives this systematic difference between siblings and only children? Our graphical portrayal reveals that only children and siblings respond differently to variables that measure the degree of parental dependency in the near future (as captured by the parameter $\rho$ ). Consider the - arguably intuitive - reaction of an only child. The more likely it is that a parent needs a substantial amount of care in the near future (i.e., the older the parent, all else equal), the lower the probability that an only child moves away from the parents. In contrast, a child with a sibling does not respond to a higher level of parental dependency by staying close to her parents. This lack of responsiveness seems counterintuitive at first. The intuition, however, is straightforward. Adult siblings negotiate over how to share caregiving responsibilities when parental needs for support are high. Bargaining power is bound up in this process. The sibling who lives closer to the parent and has a lower wage finds herself more implicated in caregiving than the other. This translates into strategic incentives for both siblings to actually move away to where high-valued employments are. The fact that siblings - unlike only children - do not have an incentive to stay close to their parents when the need for care is likely to intensify in the near future can thus be seen as evidence of the sibling power effect. When investigating whether our results are driven by the sibling power effect, we will therefore test the following:

PREDICTION 3 The more likely it is that a parent needs a substantial amount of care in the near future (the older the parent, all else equal), the lower the probability that an only child locates away from the parents. The location pattern of siblings, in contrast, is not significantly negatively correlated with variables that proxy the degree of parental dependency.

When comparing different child types, we would therefore expect that the higher the measure of expected parental dependency, the larger the differences in the location patterns between only children and siblings.

born siblings [Region $B(2)$ ]. Theoretically, the reason is that firstborn children make their location decisions first, thereby influencing the decisions of the second born child (see Konrad et al. [2002]). We will be more specific about this potential birth-order effect in the next section. 


\section{EMPIRICAL ANALYSIS}

6.1. Data. The main data source used in this analysis is the German Socio-Economic Panel Study (SOEP). ${ }^{11}$ In 1984, this longitudinal survey began interviewing a national sample of approximately 6000 households in the Federal Republic of Germany. In 1990, the SOEP was expanded to the territory of the German Democratic Republic (GDR), including nearly 2200 new households. Individuals are re-interviewed each successive year, and in the year a child in a sample household turns 16, she is interviewed in her own right. Similarly, if individuals leave their original household to form a new one, all adults of this new household are interviewed. Thus, the SOEP sample remains broadly representative of the whole population in Germany as it changes over time.

In the years 1991, 1996 and 2001, the SOEP asked specific social network questions. In particular, respondents were asked about the residential distance to their relatives. This enables us to construct our main outcome variable, namely, the geographic distance between adult children and their parents. The dependent variable, denoted $D \in\{1,2,3,4\}$, distinguishes whether a child lives in the same household, house, or neighborhood as the parents $(D=1)$, in the same town, but more than 15 minutes walk away $(D=2)$, in a different town, but less than 1 hour of travel time away $(D=3)$, or further away $(D=4) .{ }^{12}$

We use the SOEP to construct a rich intergenerational data set covering adult children from one and two-child families and their parents. The sample used in the analysis consists of 631 biological children who finished their general education, are aged at least 25 and have mothers who are SOEP respondents themselves. We restrict the sample to adult children from one and two-child families so as to present estimates based on a sample which mirrors our model environment. The selection criterium of choosing children whose mothers are SOEP respondents themselves is introduced to guarantee that information on parents directly comes from the mother and father. ${ }^{13}$ The selection criteria of including adult children who have finished their education and are at least 25 years old are imposed to guarantee that location decisions do not reflect educational choices such as a student's geographic move to a city with an university.

As a set of background variables which might affect a person's geographic mobility, we also include several socio-economic characteristics of adult children and their parents. On the children's side, we include age, sex, year of birth, marital status, foreigner, higher educational degree, the presence and number of children aged 14 and less, and the region of residence (East versus West Germany) as control variables. The variable "higher ed-

\footnotetext{
${ }^{11}$ For detailed information on the SOEP methodology, representativeness, and weighting see HaiskenDeNew and Frick [2003] and Burkhauser et al. [1997].

${ }^{12}$ In the few cases in which the distance between children and their parents is observed in more than one wave, we use the last year in which the information is available in the panel. As a result, 75 percent of the child-parent distances are measured in the year 2001, 23 percent come from the year 1996, and 2 percent from the year 1991. If the mother and father live at a different location, then the child-parent distance is measured between the mother and the adult child.

${ }^{13}$ See Parsons [1975] for the advantages of self-reported information from both generations.
} 
ucational degree" is a dichotomous variable which equals one if the person received the Abitur, a technical college degree or an university degree and is zero otherwise. ${ }^{14}$ The variable "foreigner" equals one if the person does not have the German nationality and is zero otherwise. Finally, the variable "East Germany" is a dichotomous variable indicating whether the adult child lives in the region of the former German Democratic Republic.

The empirical work also demands a proxy for $\rho$ in the model, the measure of expected parental dependency. Our principal measure is the age of the oldest parent: as we increase the age of the oldest parent, caregiving responsibilities should be more imminent for adult children, increasing the weight attached to the possibility of being implicated in eldercare in the near future. We also include the mother's marital status and parental home-ownership as additional factors that might influence the mobility pattern of young adults.

We construct two labor market variables with the aim of capturing the economic circumstances and prospects in a person's home region. Our first measure is a dummy variable which equals one if the unemployment rate in the parents' federal state is above 9 percent and is zero otherwise. Our second measure divides Germany into urban and rural areas. An urban area is defined to be a city with more than 50,000 inhabitants. ${ }^{15}$ Standard economic reasoning would suggest that adult children from economically disadvantaged regions (high unemployment or rural areas) are likely to see a potential for increased life-time earnings by moving away from their parents' locality. Summary statistics are provided in the Appendix.

Before we present the results from our multivariate analysis, we provide some first descriptive insights into our theoretical predictions. Figure 3 shows the geographic distance between children and their parents for different child types. The figure reveals that both firstborn and second born siblings locate on average further away from their parents than only children. For example, only 41 percent of siblings live in the same town than their parents, compared to 63 percent of only children. Independence tests between children with a sibling and only children lead to a clear rejection of the null hypothesis that the distance categories are statistically independent between siblings and only children. Simple descriptive statistics also suggest a systematic difference in labor market outcomes between only children and siblings. Table 1 shows that siblings from high unemployment or rural areas have higher labor earnings than only children. Only children have a higher chance of being unemployed and economically inactive compared to siblings. Moreover, the proportion of adult siblings working full-time exceeds those of only children. ${ }^{16}$ While these first casual observations seem to be in line with our predictions, nothing can be inferred from

\footnotetext{
${ }^{14}$ The Abitur is a school leaving certificate for those who successfully completed a Gymnasium - the most academically demanding secondary school track in Germany. In an alternative specification, we have used dummies for 5 different educational attainments. All our results are robust to the inclusion of this alternative measure.

${ }^{15}$ We examined the sensitivity of our results by choosing alternative thresholds, i.e. unemployment rates of 8 and 10 percent as cut-off values.

${ }^{16}$ The null hypothesis that the means of the labor market variables are equal for only children and siblings is rejected for all outcome comparisons when applying mean equality tests.
} 
the results as they might be influenced by other socio-economic characteristics neglected so far in the analysis. We now turn to a more careful examination of the data.

6.2. Baseline Results. In this section we provide evidence for the main implications of the model. Our baseline result concerns the determinants of the geographic distance between adult children and their parents. We estimate a parametric ordered probit model. ${ }^{17}$ Let $X$ be a set of socio-economic controls. Let $F$ denote being a firstborn sibling, while $S$ denotes being a second born sibling. The baseline specification is a latent variable model of the form ${ }^{18}$

$$
D^{*}=\varphi_{1} X+\varphi_{2} F+\varphi_{3} S+\varepsilon
$$

The dependent variable is the geographic distance between an adult child and her parents. ${ }^{19}$ The reference category are only children. The basic prediction of the model is that both $\varphi_{2}$ and $\varphi_{3}$ are positive significant (siblings locate on average further away from their parents than only children).

Baseline estimation results are collected in Table 2 where column (1) displays the estimated coefficients of equation (11) and column (2) the corresponding standard errors. Our first key result is that both $\varphi_{2}$ and $\varphi_{3}$ are highly significant and positive. In other words, children with a sibling consistently locate further away from their parents than only children. ${ }^{20}$ As for our control variables, having a higher educational degree and being married is associated with higher geographic mobility. In contrast, parental home ownership and being female is negatively correlated with geographic mobility. We will examine the relationship between the age of the oldest parent, which is our proxy for the parameter $\rho$ in the model, and geographic mobility in more detail in Section 6.3. To provide an quantitative interpretation of the estimated coefficients, we compute the marginal effects of having a sibling. The results - which are shown in Table 3 - provide strong evidence in line with our basic prediction. A child with a sibling has on average a 15 percent lower chance of living in the same household, house or neighborhood than an only child. The exact probabilities for firstborn and second born siblings amount to 12 and 17 percent, respectively. Conversely, for siblings, the probability of locating in the highest distance category is 5 to 7 percent higher than for only children.

The above results indicate that adult siblings consistently locate further away from their parents than only children. According to our model, this pattern is primarily driven

\footnotetext{
${ }^{17}$ We also examined a semi-parametric ordered probit model using a series estimator developed by Gallant and Douglas [1987] and Stewart [2004]. The results were similar to the ones reported here and may be obtained from the authors upon request.

${ }^{18}$ For notational convenience, we drop the subscript $i$ which indicates the individual.

${ }^{19}$ More precisely, $D^{*}$ is an unobserved latent variable which is linked to the observed ordered response distance variable $D \in\{1,2,3,4\}$ if $\eta_{D-1} \leq D^{*}<\eta_{D}$. The $\eta$ 's are threshold parameters to be estimated assuming that $\eta_{0}=-\infty$ and $\eta_{4}=+\infty$.

${ }^{20}$ We cannot reject the hypothesis that the coefficients for firstborn and second born children are equal. The $p$-value from a $\chi^{2}$-test that $\varphi_{2}=\varphi_{3}$ is 0.267 .
} 
by the fact that children with a sibling are more likely than only children to respond to poor economic prospects in their home region by moving away from the parents. To study this, we run separate regressions of the form

$$
D^{*}=\chi_{1} X+\chi_{2} F \cdot H+\chi_{3} S \cdot H+\varepsilon
$$

and

$$
D^{*}=\psi_{1} X+\psi_{2} F \cdot L+\psi_{3} S \cdot L+\varepsilon
$$

The variable $H$ in (12) is a dummy variable which takes the value 1 if parents live in a region with high unemployment or in a rural area. Conversely, the variable $L$ in (13) is a dummy which equals 1 if parents live in a region with low unemployment or in an urban area. Our model predicts that both $\chi_{2}$ and $\chi_{3}$ are significant positive. ${ }^{21}$

The results are given in Table 4. Column (1) contains estimated coefficients, while marginal effects for adult children from high/low unemployment regions are reported in column (2). The first two rows in column (1) report estimates from equation (12), whereas the last two contain estimated results from equation (13). Coefficients in each row represent results from separate regressions. Clearly, siblings from high unemployment or rural areas locate on average further away than only children. Column (2) reports the corresponding marginal effects. The exercise confirms that the results are not only statistically significant, but also quantitatively important. For example, siblings from high unemployment regions have a 12 to 20 percent higher chance of leaving the parents' house or neighborhood compared to only children. What is more, for children with a sibling, the probability of locating in the two highest distance categories is 11 to 19 percent higher than for only children. Once we compare child types from regions with low unemployment, no significant differences in children's mobility patterns are found.

Our results provide quite strong evidence that being a child with a sibling is associated with higher geographic mobility. We now take our analysis a step further. Consistent with the finding that different child types display different propensities to leave their home region, one would expect that siblings from areas with poor economic prospects (high unemployment or rural areas) display better labor market outcomes than only children. We examine four outcome variables, namely, labor earnings, full-time employment, unemployment and economic inactivity. Since these labor market outcomes are observed every year in the SOEP, we are able to estimate panel regressions here.

The results are in Table 5. We start by looking at adult children's labor earnings [Column (1)]. We estimate random effects panel earnings equations, assuming that the random effects capture individual-specific factors such as motivation and temperament.

\footnotetext{
${ }^{21}$ Note that the reference category for equation (12) are only children from high unemployment or rural areas. That is, the regression also includes the interaction terms $F \cdot L, S \cdot L$ and $O \cdot L$, where $O$ denotes being an only child. In contrast, the reference group for (13) are only children from low unemployment or urban areas. Again, regressions include a full set of interaction terms.
} 
Our sample consists of all person-year observations where children work full-time and are age 25 years and older. One striking result that can be seen from Table 5 is that siblings from high unemployment regions have a whopping 10 percent higher labor earnings than only children; similarly, siblings from rural areas display 7 percent higher earnings compared to only children. Both results are highly significant, controlling for the socio-economic variables discussed above.

We next present and discuss the marginal effects of panel probit models for our discrete outcome variables [Columns (2) to (4)]. Notice that not only are the signs of the estimated coefficients in line with our predictions, but the results are also highly significant. For example, an adult sibling from a high unemployment region (rural) has a 10 percent higher chance of being full-time employed compared to an only child from a comparable region. Moreover, a child with a sibling also has a significant lower probability of being unemployed and economically inactive.

Finally, the evidence presented in Table 4 suggested that adult children from low unemployment and urban areas do not significantly differ in their mobility pattern. Consistent with this observation, the differences in labor market outcomes almost entirely disappear once we compare child types from low unemployment and urban areas.

6.3. Inspecting the Mechanism. Our predictions, so far, are confirmed by the data. In this subsection, we turn to the channels whereby siblings differ from only children. Following the model, we analyze how adult children respond to the age of the oldest parent - our proxy of expected parental dependency in the model. We start with a simple exercise by running separate equations for only children and siblings of the form

$$
D_{\text {only }}^{*}=\phi_{1} X+\phi_{2} A+\varepsilon \quad \text { and } \quad D_{\text {sib }}^{*}=\xi_{1} X+\xi_{2} A+\varepsilon .
$$

where $A$ denotes the age of the oldest parent. For only children, the model predicts that $\phi_{2}$ is significant negative. That is, the geographic mobility of only children is negatively correlated with variables that proxy the degree of parental dependency. Siblings, in contrast, do not have an incentive to stay closer to the parents when the need for care is likely to intensify in the near future. Thus, the coefficient $\xi_{2}$ is expected not to be statistically negative significant. Table 6 shows our results for (14). The estimates support the mechanism highlighted in the model: the age of the oldest parent has a highly significant negative effect on the geographic mobility of only children; the mobility pattern of siblings, in contrast, is not significantly affected by age of the oldest parent. ${ }^{22}$ We consider this lack of responsiveness as evidence of the sibling power effect put forward in the model.

An alternative way to test for the mechanism highlighted in the model is to actually

\footnotetext{
${ }^{22}$ Indeed, the hypothesis that the age of the oldest parent is statistically different from zero was rejected for siblings but not for only children. The $p$-value of a $\chi^{2}$-test that $\phi_{2}=0$ for only children is 0.003 . Conversely, for firstborn and second born siblings the $p$-values that $\xi_{2}=0$ are 0.237 and 0.909 , respectively.
} 
compare siblings with only children by controlling for differences in socio-economic characteristics. To do so, let us go back to the graphical portrayal of our main theoretical result in Figure 2. Consider an adult child who perceives the risk of parental dependency, $\rho$, to be very small (e.g., a child with very young parents). Holding everything else constant, the figure reveals that there is no difference between the location pattern of siblings and only children when $\rho$ is very small. However, as we increase the measure of parental dependency (i.e., the age of the oldest parent) while keeping everything else equal, the difference in the mobility pattern between only children and siblings becomes more pronounced. To test this, let us divide our children into three groups, $\rho \in\{60-, 60+, 65+\}$. The first group comprises all children whose oldest parent is younger than 60 years. The second group contains adult children whose oldest parent is 60 years or older. Finally, the third group is made up of all children whose oldest parent is 65 years or older. We estimate three equations of the form:

$$
D^{*}=\alpha X+\beta_{\rho} F \cdot I_{\rho}+\gamma_{\rho} S \cdot I_{\rho}+\varepsilon
$$

The variable $I_{\rho}$ in (15) is an indicator that takes the value 1 if the oldest parent falls in one of the three age categories and is zero otherwise. Reference categories are only children with the oldest parent in the relevant age group. ${ }^{23}$ The model predicts that $\beta_{-60}$ and $\gamma_{-60}$ do not show a statistically significant sign. In contrast, $\beta_{+60}, \gamma_{+60}, \beta_{+65}$ and $\gamma_{+65}$ are expected to be significant positive, with the magnitudes of the coefficients $\beta_{+65}$ and $\gamma_{+65}$ exceeding those of $\beta_{+60}$ and $\gamma_{+60}$, respectively. Results are collected in Table 7 where column (1) gives the estimated coefficients and column (2) the corresponding marginal effects. For siblings with young parents, we see that the coefficients $\beta_{-60}$ and $\gamma_{-60}$ are indeed insignificant. That is, siblings with young parents do not exhibit higher rates of mobility than only children. Next, we consider the mobility pattern of children with older parents. Again, the model's predictions are supported by the results - siblings with older parents are significantly more likely to locate away from their parents compared to only children. Furthermore, the higher the measure of expected parental dependency (the older the parent, all else equal), the larger the differences in the geographic mobility between only children and siblings. Overall, the pattern found here seems to mirror the graphical portrayal of our main theoretical result.

The major prediction of the model was that, irrespective of birth order, siblings symmetrically exhibit higher rates of geographic mobility than only children [Region (3) in Figure 2]. We have found very strong evidence in line with this prediction. As an aside, the model also predicted that firstborn siblings may exhibit yet higher rates of mobility than second born siblings [Region (2) in Figure 2]. Theoretically, the reason for this "birth

\footnotetext{
${ }^{23}$ For example, when comparing siblings and only children with young parents, the regression also includes the interactions $F \cdot\left(1-I_{-60}\right), S \cdot\left(1-I_{-60}\right)$ and $O \cdot\left(1-I_{-60}\right)$, where $I_{-60}=1$ if the age of the oldest parent is 60 years or younger.
} 
order effect" is that firstborn siblings make their location decisions first, thereby influencing the decisions of the second born sibling (as in Konrad et al. [2002]). Empirically, we find no evidence here that is line with the birth order effect. In fact, while children with a sibling are more mobile than only children, there is no significant difference between firstborn and second born siblings. Thus the proposition here is this: the very presence of a sibling matters a lot more than birth order.

But why is it that we don't find any evidence for the birth order effect? Doesn't this run counter to the argument that a sequential game typically exhibits a first mover advantage as in our theoretical environment? Let us look to another field of research for an answer. Psychologists have long emphasized that younger siblings typically develop abilities and traits that help them offset the older's age advantage. For example, second born siblings are less likely to identify with parents, more inclined to look for unconventional opportunities, and less risk averse than firstborn siblings (Sulloway [1996]). We consider these facts as potential explanations for why we find no significant difference in the mobility pattern between firstborn and second born siblings despite the older's first mover advantage.

6.4. Evidence for the United States. Are the above results country-specific for Germany, rather than representing a general phenomenon? To investigate this, we now provide some empirical evidence for the United States. We use the first wave of the National Survey of Family and Households (NSFH), a cross-sectional sample of adults aged 19 and older living in the US. Because the NSFH collects detailed information on the geographic distance between parents and children (reported in miles) and socio-economic characteristics for both generations it is an ideal data set to complement our findings for Germany.

We limit our sample to adult children whose mothers did not move in the last five years and who have either one child or two biological children aged 30 and above. This leaves us with a sample of 523 adult children whose socio-economic characteristics are reported by their mothers. Among those, 29 percent are only children. On average, only children locate 288 miles away from their parents' residence. In contrast, firstborn (second born) children live on average 422 (414) miles away from their parents' place. The average child is 43 years old, 52 percent are daughters, and 77 percent are married. The average age of the oldest parent is 71 years.

Estimates of tobit regressions are presented in Table 8. The results do make clear that the behavior of adult children in the US shows the same pattern as in Germany. Each column shows the coefficients of a separate regression. Column (1) contains the results for our baseline specification. It shows that children with a sibling locate further away from their parents than only children. The result is significant, controlling for a host of background variables. Column (2) presents the results for interacting siblings with having parents who live in regions with high local poverty levels. ${ }^{24}$ It shows that siblings from

\footnotetext{
${ }^{24}$ Since the NSFH provides information about local poverty levels rather unemployment rates, we use the former as a proxy for economically disadvantaged regions.
} 
disadvantaged regions are more likely to locate away from their parents compared to only children. Looking at regions with better economic prospects, no differences are found in the mobility pattern between different child types. Column (3) reports the results for interacting siblings with the age of the oldest parent. Siblings with young parents are not different in their mobility pattern compared to only children; in contrast, siblings with old parents exhibit significantly higher rates of mobility than only children. Thus, our findings for the United States appear to show again that only children and siblings differ in the way in which they respond to variables that proxy the degree of parental dependency.

6.5. Robustness, Validation and Caveats. We have subjected the results for Germany to a variety of robustness checks.

- Unobserved Heterogeneity. Readers may be concerned that our results are driven by children's characteristics which are unobservable to the researcher. To address this concern, we now present results of a random effect ordered panel model. To make use of the panel structure of the SOEP, we are relying on the following three distance categories which are available in each wave of the SOEP: child and parents live in (a) same household, (b) different household but same federal state, (c) different federal states. The results are presented in Table 9. Overall, the findings suggest that our evidence for Germany is robust to controlling for children's unobservable characteristics.

- Age Gap between Parents. The age gap between mother and father might affect children's mobility pattern. For example, having an old father might be less constraining for an adult child whose mother is young, in good health and able to look after her husband, compared to children with two elderly and frail parents. In unreported regressions, we controlled for the age gap between parents. Strikingly, we found indeed evidence that the parental age differential is positively correlated with children's geographic mobility. However, our major finding concerning the relationship between child type and geographic mobility is robust to including the parental age differential. ${ }^{25}$

- An Alternative Proxy for Expected Parental Dependency. The state of parental dependency was defined as a situation in which parents need physical or emotional support from their adult children. Our model predicted that only children and siblings respond differently to variables that measure the degree of expected parental dependency. We investigated this prediction using the age of the oldest parent as the main proxy for expected parental dependency. In unreported estimation exercises, we examined an alternative proxy: whether or not the mother is single. Our idea is that children with single mothers attach more weight to the possibility of having to satisfy the social needs of the parent than children

\footnotetext{
${ }^{25}$ We also controlled for the influence of alternative potential care providers (such as whether parents have relatives other than children in the same town ), the age gap between siblings and various health measures for both children and their parents such as disability, number doctor visits in the previous 3 months or hospital stay in the previous year. Moreover, we included parental household income and whether or not parents are self-employed as explanatory variables. The results where insensitive to the inclusion of these additional controls.
} 
with married parents. The prediction of the model would be that the mobility pattern of only children is negatively correlated with the mother being single, while the mobility pattern of siblings is not negatively affected by having a single mother. Our results did confirm this prediction. Consistent with the results reported in Table 7, the estimation showed that siblings with a single mother have a 17 percent higher chance to locate in the highest distance category compared to only children with a single mother. No significant difference is found between siblings and only children whose parents are married.

- Leaving the Nest. Recent years have witnessed a trend towards older age at which children leave their parents' home (Szydlik [2000], Wagner and Huinink [1991]). Suppose for a moment that this is in particular true for only children. Then our findings might be driven by the fact that only children leave their parental home later than children with a sibling. To account for this possibility, we experimented with the age of children and extracted samples of older children (i.e., children aged 26,27,28,29,30). While this exercise did lead to smaller sample sizes, it did not disturb our basic result that siblings are more likely to locate away from their parents than only children.

- Siblings' Sex Composition. Previous studies find that middle age daughters are most likely to be the primary caregiver (Checkovich and Stern [2002]). It is thus interesting to investigate whether mobility pattern of young adults differ by gender. To examine this, we re-estimated our model by comparing the location decisions of male and female siblings with that of only children. In unreported regressions, we found that both daughters and sons from two-child families show a significant higher propensities to locate in a high distance category compared to only children.

- Parents' Geographic Mobility. For simplicity, our theoretical model assumes that parents are inactive, i.e., they are not allowed to move. This might appear as a restrictive assumption and the reader might object with it. However, the assumption is entirely in line with stylized mobility facts in Germany. In fact, less than 3 percent of households with a member older than 60 years move house every year. ${ }^{26}$

- Caveats. It is important to air some caveats. First, for the most part of our empirical analysis, we observed the geographic distance between adult children and their parents at given points in time. Thus, we were not able to provide a complete picture of mobility patterns over children's entire lifespan. Second, we did not find a valid instrument (such as twins) for an exogenous variation in family size. This would have helped us to unravel more of a causal relationship than the present estimates do. Finally, our empirical results are based on relatively small sample sizes. ${ }^{27}$

\footnotetext{
${ }^{26}$ This figure is based on own calculations using SOEP data from 2004.

${ }^{27}$ However, we repeated the descriptive exercise in Section 6.1 without restricting the sample to children whose parents are SOEP respondents. This did yield considerable larger sample sizes. For example, when we extracted adult children aged 40 or older, our sample consisted of 1730 only children and 7025 siblings. Irrespective of the particular age threshold used in the sample selection, the percentage of siblings locating in higher distance categories always significantly exceeded those of only children.
} 


\section{Discussion}

The results presented above deliver a number of specific insights, some of which we have already discussed. We now highlight the major points more generally and present implications that are relevant to some.

- Demographic Trends in Europe and Geographic Mobility. Geographic mobility in the EU is relatively low, both between and within member states. Within member states, in spite of persistent regional labor market disparities, there is often little movement to regions with lower unemployment and higher income. Unsurprisingly, improving the potential for mobility is high on the policy agenda. For example, it is well understood that in many EU member states, centralized wage agreements need to take better account of regional differences in productivity and labor market conditions; reforms of unemployment benefit systems are necessary to give people an incentive to move to a location where they can get a job; the functioning of the housing market needs to be improved by cutting transaction costs, such as taxes and fees for real estate agents, notaries and land registration.

However, in thinking about what different policy options are out there for increasing the potential for geographic mobility, it has not been considered before that any such policy may be hampered by demographic trends which are currently reshaping family structures in virtually any EU country. Here we mention two such trends. The first is the trend toward delayed first childbirth. The second is the decline in fertility rates and the growing trend towards one-child families, commonly referred to as the emergence of the "beanpole family". The first trend matters because it boosts the average age at which women have children and thus increases the mean parent-child age difference. The trend towards one-child families matters because only children (unlike siblings) respond to an increase in the parent-child age difference by staying close to their parents, even if they thereby forfeit better career prospects in regions with lower unemployment and higher income. Hence it is conceivable that the force toward delayed first child birth, and the decline in fertility rates, are likely to be obstacles to geographic mobility in the future. It thus follows that the policy options mentioned above may not be sufficient in generating higher levels of geographic mobility. In fact, the lesson for policy-makers here is this: with families shrinking horizontally and fewer siblings around, what is needed is a strategy for sharing the burden of elder care between adult children and the state; for, otherwise, the number of people who will be limited to move very far because of familial obligations might dramatically decrease the potential for mobility as an equilibrating economic mechanism.

- Geographic Mobility in Europe and the US. It is a stylized fact that mobility rates in Europe are low compared to the US. Major reasons usually put forward to explain this difference include a combination of relatively high aggregate unemployment, intrinsic preferences against mobility, and policy-induced distortions (Braunerhjelm et al. [2000]). Our results suggest that there is a case to argue that the lower mobility in Europe can to an extent also be explained by two demographic factors. First, at the end of the 1990s, 
the total fertility rate was about 1.31 children per woman in Germany while the U.S. rate was 2.04. Second, the mean age of mother at first birth in the United States was 24.9 in 2000, while in Germany the mean age was 29.0 years (Mathews and Brady [2002], Council of Europe [2001]). Trying to understand the difference in mobility rates between Europe and the United States without taking these demographic fundamentals into account could be quite deceptive and lead to biased results. What goes along with lower fertility rates in Europe is the increasing prevalence of only child families. The higher parent-child age differential in Europe might mean that the average European child perceives caregiving responsibilities to be more imminent than the average child in the United States. The demographic explanations might at least partially contribute to lower mobility rates in Europe compared to the United States. To shed more light on this issue, a cross-country assessment is required, which we leave for future research.

\section{Conclusion}

Adult children represent the largest proportion of primary caregivers of older persons, devoting significant amounts of time providing care. This paper examines how long-term care responsibilities and family structure interact in affecting child mobility characteristics. We argue that having a sibling can have a profound impact on one's geographic mobility and labor market outcomes. Two ideas take center stage in our story: that young adults make decisions relative to long-term care decisions long before the actual care is needed; and that strategic interactions which are to be found in the relationship between siblings for example, their striving for "say" in parental care decisions - have a determinate effect on their mobility pattern.

We concluded from our theoretical analysis that the location choices of siblings interact with family care decisions at later stages so as to cause an equilibrium in which siblings not only exhibit higher rates of mobility than only children, but also have better labor market outcomes. Evidence based on data from Germany and the United States showed that having a sibling has indeed a statistically significant positive effect on geographic mobility and labor market outcomes. Clearly, a great deal more research is needed to understand how long-term elder care decisions and family structure interact in affecting child mobility characteristics. But for economists who are interested in patterns of geographic mobility, it may be important to pay closer attention to our most universal social institution - the family.

\section{REFERENCES}

[1] Admati, Anat R. and Perry, Motty. "Joint Projects without Commitments," The Review of Economic Studies, 58 (1991), 259-276. 
[2] Antolin, Pablo and Bover, Olympia. "Regional Migration in Spain: the Effect of Personal Characteristics and of Unemployment Wage and House Price differentials using pooled cross sections," Oxford Bulletin of Economcs and Statistics, 59 (1997), 215-235.

[3] Bertola, Giuseppe. "Microeconomic Perspectives on Aggregate Labor Markets," in Orley Ashenfelter (ed.), Handbook of Labor Economics (Amsterdam: Elsevier, 1999).

[4] Braunerhjelm, P.; Faini, R.; Norman V.; Ruane, F. and Seabright, P. Integration and the Regions of Europe: How the Right Policies Can Prevent Polarization. (London: CEPR, 2000).

[5] Burkhauser, Richard V.; Kreyenfeld, Michaela and Wagner, Gert G. "The German Socio-Economic Panel: A Representative Sample of Reunited Germany and its Parts", DIW/Vierteljahresbericht,66 (1997), 7-16.

[6] Checkovich, Tennille J. and Stern, Steven. "Shared Caregiving Responsibilities of Adult Siblings with Elderly Parents", Journal of Human Resources, 37 (2002), 441478.

[7] Clark, David; McKeon, Amy; Sutton, Matt and Wood, Rachael. "Healthy Life Expectancy in Scotland," Information and Statistics Divsion, NHS Scotland, 2004. Availabe online at: 〈http://www.isdscotland.org/isd/files/HLE_report_2004.pdf $\rangle$. Accessed July 23, 2005.

[8] Couch, Kenneth A.; Douglas, Mary C. and Wolf, Douglas A. "Time? Money? Both? The Allocation of Resources to Older Parents," Demography, 36 (1999), 219232.

[9] Council of Europe, "Recent Demographic Trends in Europe 2002," Strasbourg: Council of Europe Publishing, 2002.

[10] Engers, M. and Stern, Steven. "Long-term Care and Family Bargaining", International Economic Review 43 (2002), 73-114.

[11] Ermisch, John. "Parent and Adult-Child Interactions: Empirical Evidence from Britain," Working Papers of the Institute for Social and Economic Research, paper 2004-02. Colchester: University of Essex.

[12] Gallant, Ronald A. and Nychka, Douglas W. "Semi-Nonparametric Maximum Likelihood Estimation", Econometrica, 55 (1987), 363-390.

[13] Gregg, Paul; Machin, Stephen and Manning, Alan. "Mobility and Joblessness," in Richard Blundell et al. (eds.), Seeking a Premier League Economy (National Bureau of Economic Research, 2004). 
[14] Haisken-DeNew, John P. and Frick, Joachim R. "Desktop Companion to the German Socio-Economic Panel Study (GSOEP)"(DIW-Berlin, 2003).

[15] Konrad, Kai A.; Künemund, Harald; Lommerud, Kjell E. and Robledo, Julio R. "Geograpy of the Family," The American Economic Review, 92 (2002), 981998.

[16] Mathews, T. J. and Hamilton, Brady E. "Mean Age of Mother, 1970-2000," National Vital Statistics, 51 (2002), 1-16.

[17] Muthoo, Abhinay. Bargaining Theory with Applications (Cambridge: Cambridge University Press, 1999).

[18] National Alliance for Caregiving and AARP. "Caregiving in the U.S.," 2004. Available online at: 〈http://www.caregiving.org/data/04finalreport.pdf $\rangle$. Accessed Septermber 5, 2005.

[19] Nickell, Steve, and Layard, Richard. "Labor Market Institutions and Economic Performance," in Orley Ashenfelter (ed.), Handbook of Labor Economics (Amsterdam: Elsevier, 1999).

[20] Oswald, Andrew. "A Theory of Homes and Jobs," University of Warwick, mimeo, 1997.

[21] Parsons, Donald O. "Intergenerational Wealth Transfers and the Educational Decisions of Male Youth", Quarterly Journal of Economics, 89 (1975), 603-617.

[22] Pezzin, Liliane E. and Schone, Barbara. "Intergenerational Household Formation, Female Labor Supply and Informal Caregiving," Journal of Human Resources, 34 (1999), 475-503.

[23] Pezzin, Liliana E.; Pollak, Robert A. and Schone, Barbara. "Long-Term Care and Family Decision Making", unpublished manuscript, Agency for Healthcare Research and Quality, 2003.

[24] Rubinstein, Ariel. "Perfect Equilibrium in a Bargaining Model," Econometrica, 50 (1982), 97-110.

[25] Szydlik, Marc. Lebenslange Solidarität? Generationenbeziehungen zwischen erwachsenen Kindern und Eltern (Opladen: Leske und Budrich, 2000).

[26] Sloan, F.A., Picone, G. and Hoerger, T.J. "The Supply of Children's Time to Disabled Elderly Parents," Economic Inquiry, 35 (1997), 295-308. 
[27] Stern, Steven. "Estimating Family Long-Term Care Decisions in the Presence of Endogenous Child Characteristics," The Journal of Human Resources, 30 (1995), 551580.

[28] Stern, Steven. "Measuring child work and residence adjustments to parents' longterm care needs," The Gerontologist, 36 (1996), 76-87.

[29] Stewart, Mark B., "Semi-nonparametric Estimation of Extended Ordered Probit Models", The Stata Journal, 4 (2004), 27-39.

[30] Tatsiramos, Konstantinos. "Geographic labour mobility and unemployment insurance in Europe," IZA Discussion Paper No. 1253, 2004.

[31] Van Buuren S.; Boshuizen, H.C. and Knook, D. L. "Multiple imputation of missing blood pressure covariates in survival analysis," Statistics in Medicine 18 (1999), 681-694.

[32] Wagner, Michael and Huinink, Johannes. "Neuere Trends beim Auszug aus dem Elternhaus", in G. Buttler; H.-J. Hoffmann-Nowotny; G. Schmitt-Rink (eds.), Acta Demographica, (Heidelberg: Physica, 1991), 39-62. 


\section{Figures AND TABLES}

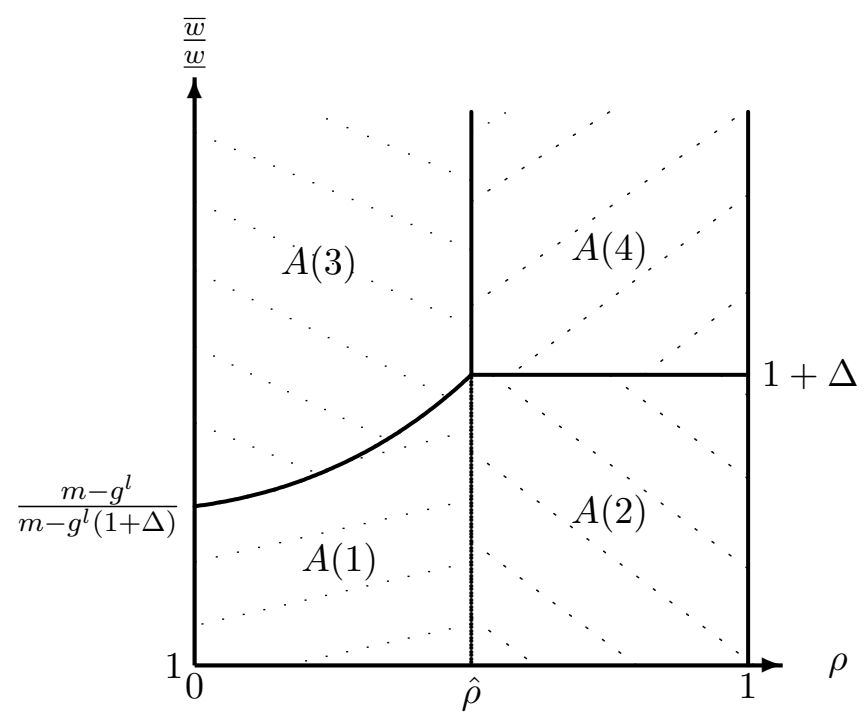

(a) Parameter values satisfying $g^{l}<$ $m /(2+\Delta)<g^{h}$.

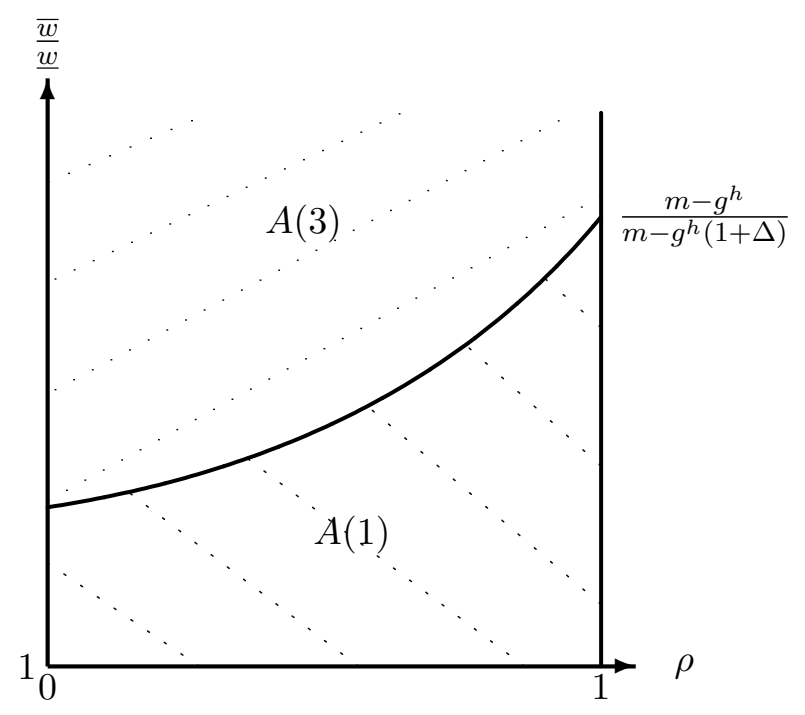

(b) Parameter values satisfying $g^{l}<$ $g^{h}<m /(2+\Delta)$.

Figure 1: Geographic Mobility of an Only Child

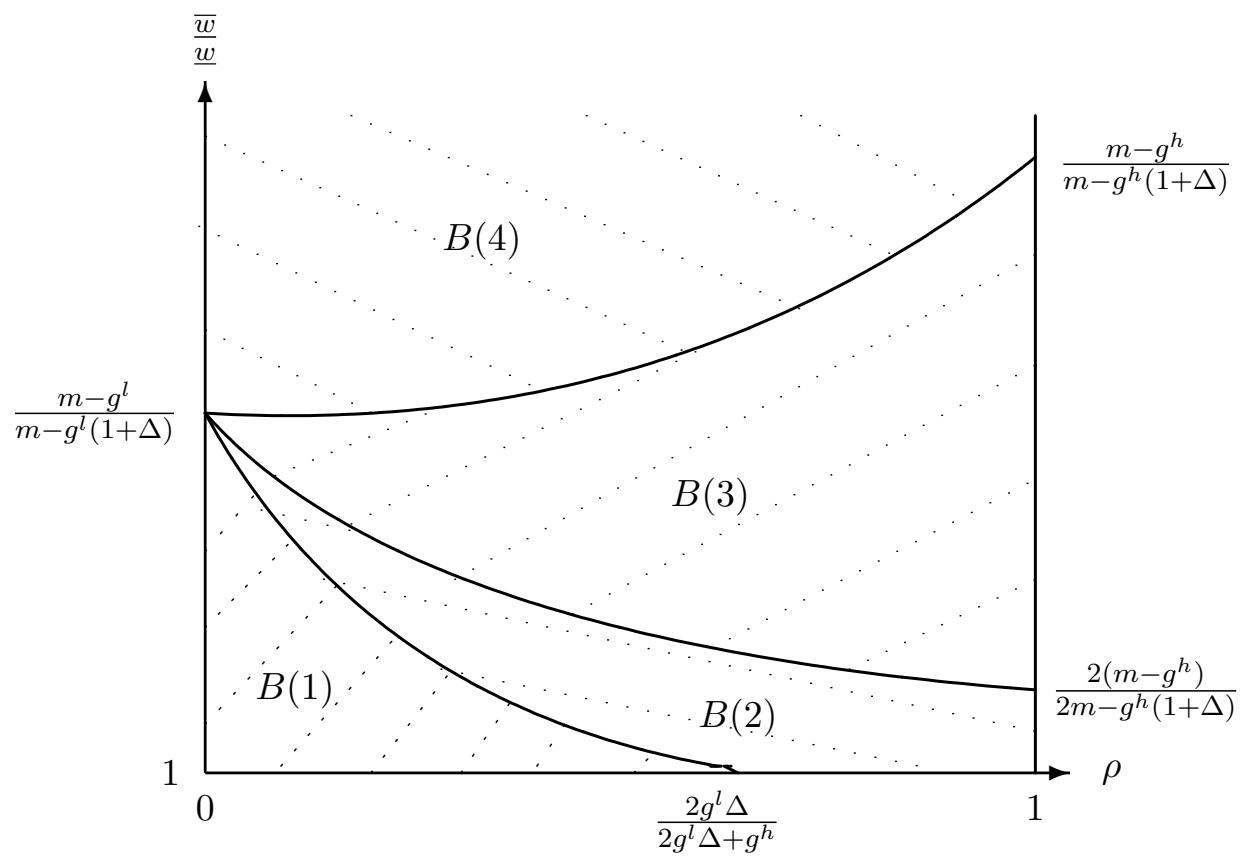

Figure 2: Geographic Mobility of Only Children v/s Siblings 


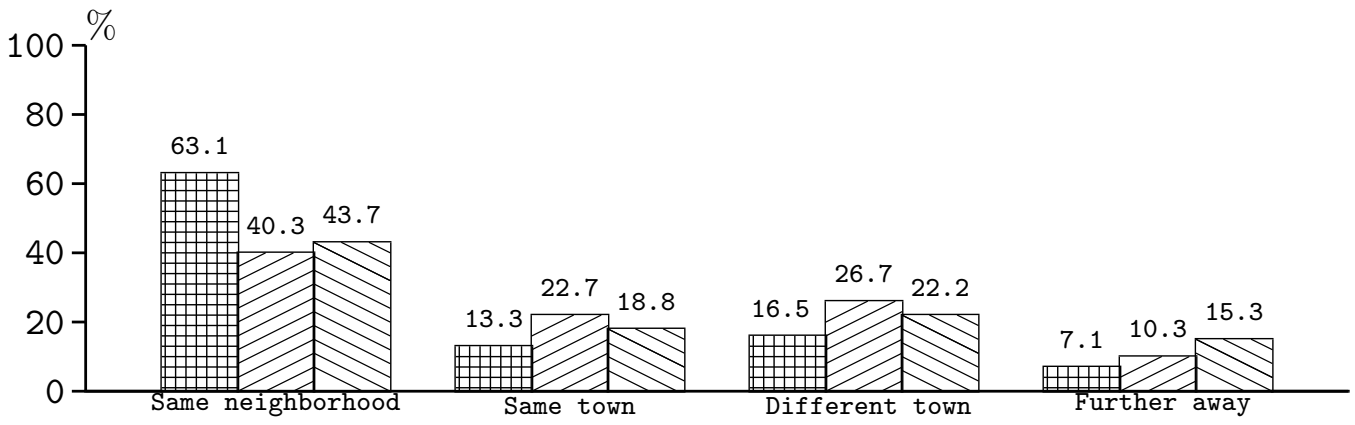

$\#$ Only Children $\bigotimes$ Firstborn $\$$ Second born

Figure 3: Geographic Distance between Parents and Children by Child Type

Table 1: Means of Labor Market Outcome Variables by Child Type (Germany)

\begin{tabular}{lcccccc}
\hline \hline & \multicolumn{2}{c}{$\begin{array}{c}\text { Parents live in high } \\
\text { unemployment region }\end{array}$} & & \multicolumn{2}{c}{$\begin{array}{c}\text { Parents live in } \\
\text { rural area }\end{array}$} \\
\cline { 2 - 3 } \cline { 5 - 6 } \cline { 5 - 6 } & Only children & Siblings & & Only children & Siblings \\
\cline { 2 - 3 } \cline { 5 - 6 } Labor earnings & 28,466 & 31,526 & & 28,398 & 32,709 \\
Unemployment & 7.6 & 4.1 & & 6.7 & 4.2 \\
Economic inactivity & 23.2 & 19.2 & & 23.4 & 17.3 \\
Full-time employment & 60.0 & 67.0 & & 59.2 & 67.3 \\
\hline
\end{tabular}

Notes: Figures are means computed on all available person-year observations where children are age 25 and above and have finished their general education. Outcome variables are observed in waves 1-20 in the SOEP. Earnings are annual labor earnings for young adults working full-time and are deflated using the Consumer Price Index and are expressed in 2001 Euros. Looking at the labor market outcomes for firstborn and second born children reveals that both child types have favorable outcomes in comparison to only children. For example, firstborn (second born) children whose parents live in federal states with high unemployment have the following outcome variables. Labor earnings: 30,871 (32,410); unemployment: 3.6 (4.8); economic inactivity: 18.9 (19.5); full-time employment: $66.2(68.6)$. 
Table 2: Determinants of Child-Parents Geographic Distance (Germany)

Coefficient Standard Error

\section{Children's Characteristics:}

$\begin{array}{lcc}\text { Age } & 0.001 & 0.023 \\ \text { Female } & -0.178^{*} & 0.098 \\ \text { Year of birth } & 0.002 & 0.021 \\ \text { Foreigner } & -0.104 & 0.216 \\ \text { East Germany } & -0.129 & 0.141 \\ \text { Married } & 0.270^{* *} & 0.114 \\ \text { Dependent children } & -0.201 & 0.205 \\ \text { Number of dependent children } & 0.102 & 0.117 \\ \text { Higher education } & 0.683^{* *} & 0.102 \\ \text { Firstborn } & 0.297^{* *} & 0.121 \\ \text { Second born } & 0.421^{* *} & 0.125\end{array}$

\section{Parents' Characteristics:}

Age of oldest parent

Mother is single

Parent(s) are homeowner

$\begin{array}{cc}-0.028^{* *} & 0.008 \\ 0.095 & 0.122 \\ -0.333^{* *} & 0.119\end{array}$

LABOR MARKET IN THE HOME REGION:

High unemployment region

Rural area
0.196

$0.224^{*}$

0.124

Threshold parameters:

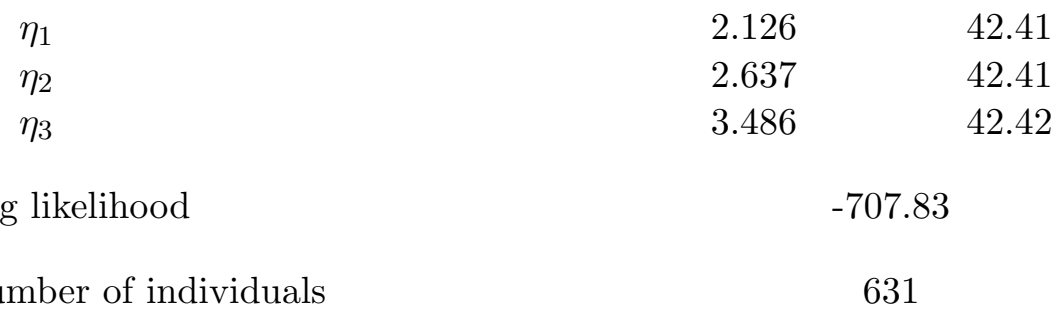

Notes: Ordered probit estimation results. The dependent variable is the geographic distance between adult children and their parents. Standard errors allow for arbitrary serial correlation. Reference categories are male, nonmarried, no children, German citizen living in West Germany, no higher educational degree, married parents living in an urban area with low unemployment, parents are not home owners, and only child. We denote significance at the 5 and 10 percent level with ${ }^{* *}$ and ${ }^{*}$, respectively. 
Table 3: The Effects of Having a Sibling on the Probability to Locate in a Certain Distance Category (Germany)

\begin{tabular}{lcc}
\hline \hline & $(1)$ & $(2)$ \\
& Firstborn & Second born \\
\hline Same household, house, neighborhood & $-0.118^{* *}$ & $-0.166^{* *}$ \\
& $(0.048)$ & $(0.049)$ \\
Same town, $>15$ min. walk & $0.014^{* *}$ & $0.017^{* *}$ \\
& $(0.006)$ & $(0.005)$ \\
Different town & $0.056^{* *}$ & $0.079^{* *}$ \\
& $(0.023)$ & $(0.023)$ \\
Further away & $0.048^{* *}$ & $0.071^{* *}$ \\
& $(0.021)$ & $(0.025)$ \\
Number of individuals & \multicolumn{2}{c}{631} \\
\hline
\end{tabular}

Notes: Estimates are marginal effects from ordered probit regressions computed at average values of all variables used. The dependent variable is the geographic distance between adult children and their parents. Robust standard errors are in parentheses.

${ }^{*}$ and ${ }^{* *}$ denote significance at the 5 percent and 10 percent level, respectively. 
Table 4: Child-Parents Geographic Distance by Economic Prospects in Home Region (Germany)

\begin{tabular}{ccc}
\hline \hline & \multicolumn{2}{c}{$(1)$} \\
& \multicolumn{2}{c}{ Estimated Coefficients } \\
\cline { 2 - 3 } & Firstborn & Second bo \\
\hline LABOR MARKET IN HOME REGION: & & \\
High Unemployment & & \\
Rural area & $0.313^{* *}$ & $0.509^{* *}$ \\
& $(0.141)$ & $(0.147)$ \\
Low Unemployment & $0.368^{* *}$ & $0.411^{* *}$ \\
& $(0.154)$ & $(0.155)$ \\
Urban area & 0.253 & 0.250 \\
& $(0.205)$ & $(0.218)$ \\
& 0.157 & $0.453^{* *}$ \\
& $(0.172)$ & $(0.194)$
\end{tabular}

Children FROM High UE REGIONS:

Same neighborhood

$\begin{array}{cc}-0.124^{* *} & -0.199^{* *} \\ (0.056) & (0.056) \\ 0.012^{* *} & 0.013^{* *} \\ (0.004) & (0.005) \\ 0.053^{* *} & 0.094^{* *} \\ (0.027) & (0.034) \\ 0.053^{* *} & 0.094^{* *} \\ (0.027) & (0.034)\end{array}$

Children from low UE REgions:

Same neighborhood

$\begin{array}{cc}-0.100 & -0.099 \\ (0.081) & (0.086) \\ 0.009^{*} & 0.009^{*} \\ (0.005) & (0.005) \\ 0.047 & 0.047 \\ (0.038) & (0.040) \\ 0.042 & 0.042 \\ (0.039) & (0.042)\end{array}$

Number of individuals

Notes: UE denotes unemployment. Ordered probit estimation results. The dependent variable is the geographic distance between adult children and their parents. Robust standard errors are given in parentheses. We only report the interactions which are of most interest, however, all regressions include a full set of interaction terms. Other covariates as in Table $2 .^{*}$ and ${ }^{* *}$ denote significance at the 5 percent and 10 percent level, respectively. 
Table 5: The Effects of Having a Sibling on Labor Market Outcomes (Germany)

(1)

(2)

$(3)$

(4)

Dependent Variables: Log Labor Full-time Economic

Earnings employment Unemployment inactivity

LM IN THE HOME REGION:

$\begin{array}{lcccc}\text { High Unemployment } & 0.095^{* *} & 0.098^{* *} & -0.004^{* *} & -0.041^{*} \\ & (0.035) & (0.048) & (0.002) & (0.024) \\ \text { Rural area } & 0.066^{* *} & 0.097^{* *} & -0.001 & -0.044^{*} \\ & (0.036) & (0.047) & (0.002) & (0.025) \\ \text { Low Unemployment } & 0.092^{* *} & 0.002 & -0.002 & -0.012 \\ & (0.037) & (0.053) & (0.002) & (0.028) \\ \text { Urban area } & 0.026 & -0.023 & -0.001 & 0.069 \\ & (0.048) & (0.071) & (0.002) & (0.043)\end{array}$

Number of person-year

observations:

2927

4616

4626

4642

Number of individuals:

506

605

605

607

Notes: Log earnings regressions are random effect panel estimations. The other estimates (column 3-5) are random effect panel probit regressions. Other covariates as in Table 4. Regressions using unemployment levels as part of the reference category do not control for region of residence due to multicollinearity problems. Standard errors are given in parentheses. ${ }^{*}$ and ${ }^{* *}$ denote significance at the 5 percent and 10 percent level, respectively.

Table 6: Child-Parents Geographic Distance by Age of the Oldest Parent (Germany)

(1)

(2)

(3)

Only Children Firstborn Secondborn

\begin{tabular}{lccc}
\hline Age of oldest Parent & $-0.039^{* *}$ & -0.001 & -0.025 \\
& $(0.013)$ & $(0.019)$ & $(0.018)$ \\
Number of individuals & 279 & 176 & 176 \\
\hline
\end{tabular}

Notes: Ordered probit estimations results. The dependent variable is the geographic distance between adult children and their parents. Figures in each row represent estimated coefficients from a different regression. Other covariates as in Table 2 excluding the dummy variables for being a firstborn or second born child. Standard errors are given in parentheses. ${ }^{*}$ and ${ }^{* *}$ denote significance at the 5 percent and 10 percent level, respectively. 
Table 7: Child-Parents Geographic Distance by Age of the Oldest Parent (Germany)

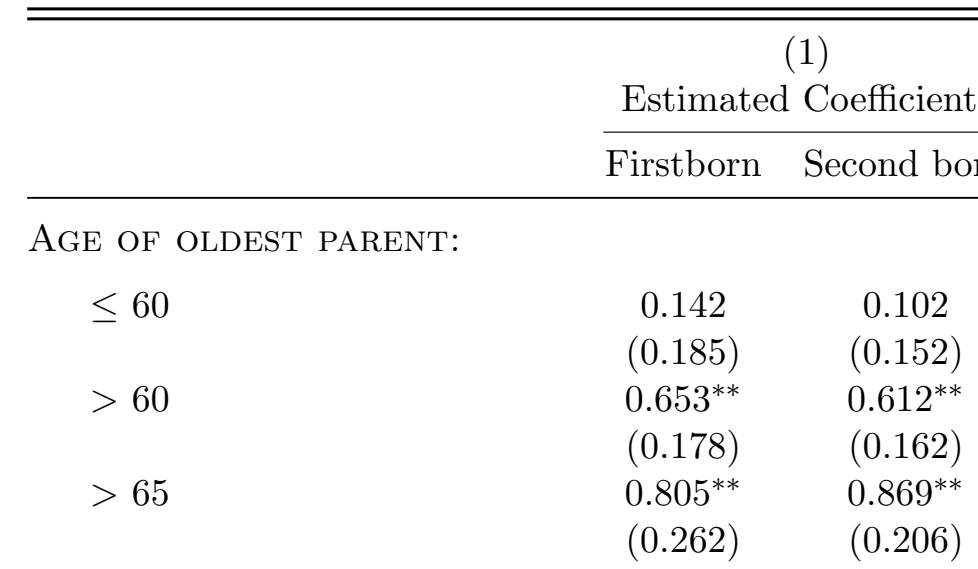

AgE OF OLDEST PARENT $\leq 60$ :

Same neighborhood

$\begin{array}{cc}-0.041 & -0.040 \\ (0.061) & (0.061) \\ 0.005 & 0.005 \\ (0.007) & (0.007) \\ 0.020 & 0.019 \\ (0.029) & (0.031) \\ 0.016 & 0.015 \\ (0.025) & (0.035) \\ & \\ & \\ -0.056 & -0.113 \\ (0.073) & (0.072) \\ 0.007 & 0.011^{* *} \\ (0.007) & (0.004) \\ 0.110^{* *} & 0.126^{* *} \\ (0.025) & (0.023) \\ 0.134^{* *} & 0.174^{* *} \\ (0.048) & (0.056)\end{array}$

Age of OLDEST PARENT $>65$ :

Same neighborhood

$\begin{array}{cc}-0.298^{* *} & -0.362^{* *} \\ (0.081) & (0.075) \\ -0.009 & -0.029 \\ (0.021) & (0.029) \\ 0.120^{* *} & 0.128^{* *} \\ (0.023) & (0.017) \\ 0.188^{* *} & 0.263^{* *} \\ (0.084) & (0.101)\end{array}$

Same town, $>15$ min. walk

Different town

\author{
Marginal Effects
}

Firstborn Second born

Same town, $>15$ min. walk

Different town

Further away

AGE OF OLDEST PARENT > 60:

Same neighborhood

Same town, $>15$ min. walk

Different town

Further away

Further away

(0.084)

(0.101)

Number of individuals

631

Notes: Ordered probit estimation results. The dependent variable is the geographic distance between adult children and their parents. Estimates in each row represent coefficients or marginal effects from a different regression. Robust standard errors are given in parentheses. We only report the interactions which are of most interest, however, all regressions include a full set of interaction terms. Other covariates are as in Table 2. * and ${ }^{* *}$ denote significance at the 5 percent and 10 percent level, respectively. 
Table 8: Child-parents Geographic Distance by Child Type, Economic Prospects in Home Region and Age of the Oldest Parent (United States)

\begin{tabular}{lcc}
\hline \hline & $(1)$ & $(2)$ \\
& Baseline & Prediction \\
\hline & & \\
Firstborn & $0.189^{*}$ & \\
Second born & $(0.100)$ & \\
& $0.191^{*}$ & \\
Firstborn $\times$ Poor Region & $(0.102)$ & \\
& & \\
Second born $\times$ Poor Region & & $0.511^{*}$ \\
& & $(0.277)$ \\
Firstborn $\times$ Non-Poor Region & & $0.590^{* *}$ \\
& & $(0.278)$ \\
Second born $\times$ Non-Poor Region & & 0.144 \\
& & $(0.107)$ \\
& & 0.149 \\
& & $(0.108)$
\end{tabular}

Firstborn $\times$ Young Parents $\quad-0.017$

Second born $\times$ Young Parents

Firstborn $\times$ Old Parents $\quad 0.386^{* *}$

Second born $\times$ Old Parents $\quad 0.234^{*}$

Number of individuals

523

Notes: Tobit estimation results. The dependent variable is the geographic distance between adult children and their parents in miles. Each column presents results from one regression. Coefficients are divided by 1000. Regressions also include indicators for children's age, sex, marital status, children's highest educational degree, mother's marital status, parental homeowernship and race of mother. The first two regressions also control for two local labor market variables. The first one is a dichotomous variable which equals one if parents' live in a non-metropolitan area and is zero otherwise. The second labor market variable ('poor' home region) is a dichotomous variable which equals one if more than 15 percent of families in the county have an income below the poverty line and is zero otherwise. Similarly, the third regression also controls for whether parents live in a non-metropolitan area or not. Children's educational information comes from wave 2 of the NSFH. Missing values are imputed via multivariate imputation using regression switching (van Buuren et al. [1999]). A "young" parent is defined as being younger than 70. An "old" parent is defined as being older than $70{ }^{*}$ and ${ }^{* *}$ denote significance at the 5 percent and 10 percent level, respectively. 
Table 9: Child-Parents Geographic Distance by Child Type, Economic Prospects in Home Region and Age of the Oldest Parent (Germany)

\begin{tabular}{cccc}
\hline \hline$(1)$ & $(2)$ & $(3)$ \\
Baseline & Prediction 1 & Prediction 3
\end{tabular}

Firstborn $\quad 0.197^{*}$

Second born $1.229^{* *}$

$(0.139)$

Firstborn $\times$ High UE $0.272^{*}$

Second born $\times$ High UE

$(0.151)$

$(0.177)$

Firstborn $\times$ Low UE $\quad 0.112$

Second born $\times$ Low UE $\quad 0.228$

$(0.176)$

Firstborn $\times$ Young Parents $\quad-0.155$

Second born $\times$ Young Parents

$-0.137^{* *}$

Firstborn $\times$ Old Parents $\quad 0.586^{* *}$

Second born $\times$ Old Parents $\quad 1.521^{* *}$

Number of person-year observations $\quad 4642$

Number of individuals $\quad 631$

Notes: Random effect ordered probit estimation results. The dependent variable is the geographic distance between adult children and their parents, consisting of the following three distance categories: (a) same household, (b) different household but same federal state, (c) different federal state. Sample includes person-year observations of adult children who are aged 25 years and older and who have finished their general education. Other control variables are as in Tables 2,4 and 7 . * and ${ }^{* *}$ denote significance at the 5 percent and 10 percent level, respectively. A "young" parent is defined as being younger than 60. An "old" parent is defined as being older than 60 . 


\section{Appendix A: THEORY}

Proof of Result 1. Fix an arbitrary location choice $l_{o} \in[\underline{x}, \bar{x}]$ and employment choice $e_{o} \in\{\underline{x}, \bar{x}\}$ made by child $o$ in period 1. Assume that the underlying parameters are such that $c_{o}\left(g^{k}\right)+G^{k}>c_{o}(0)$ for all $k \in\{l, h\}$; for otherwise there are no gains to providing the required amount of care. The payoff to child $o$ at the end of period 2 in each state $k$ (where $k=l$ or $k=h$ ) will be as in equations (4) and (5) in the main text, but with $s_{i}^{k}$ replaced by $g^{k}$. In period 1 , child $o$ maximizes expected utility $\mathbf{E}_{o}=(1-\rho) u_{o}^{l}+\rho u_{o}^{h}$ by location choice $l_{o} \in[\underline{x}, \bar{x}]$ and employment choice $e_{o} \in\{\underline{x}, \bar{x}\}$. For explicitness, note that

$$
\mathbf{E}_{o}\left(l_{o}, e_{o}\right)=\frac{w_{o}}{1+\delta_{o}^{e}}\left[m-\left(1+\delta_{o}^{p}\right)\left[g^{l}+\rho\left(g^{h}-g^{l}\right)\right]\right]+\left[G^{l}+\rho\left(G^{h}-G^{l}\right)\right]
$$

where $\delta_{o}^{p}=\left|l_{o}-\underline{x}\right|$ and $\delta_{o}^{e}=\left|l_{o}-e_{o}\right|$. Since

$$
\frac{\partial \mathbf{E}_{o}\left(l_{o}, e_{o}\right)}{\partial l_{s}} \gtrless 0 \Longleftrightarrow w_{o}\left[-m+\left(e_{o}-\underline{x}\right)\left[g^{l}+\rho\left(g^{h}-g^{l}\right)\right] \gtrless 0,\right.
$$

it follows immediately that child $o$ will choose to locate at one extreme of the economy, that is, either at $\underline{x}$ or at $\bar{x}$. As a consequence, the equilibrium location and employment decisions of $o$ are based on comparing the four states of the world, $l_{o}=\underline{x}$ or $l_{o}=\bar{x}$ combined with $e_{o}=\underline{x}$ or $e_{o}=\bar{x}$. Under Assumption 1 , the expected payoffs from the four actions $\left(l_{o}, e_{o}\right) \in\{\underline{x}, \bar{x}\} \times\{\underline{x}, \bar{x}\}$ are respectively given by

$$
\mathbf{E}_{o}\left(l_{o}, e_{o}\right)=\left\{\begin{array}{llc}
\underline{w}(m-\tilde{g})+\tilde{G} & \text { if } & \left(l_{o}, e_{o}\right)=(\underline{x}, \underline{x}) \\
\bar{w}(m-\tilde{g}) /(1+\Delta)+\tilde{G} & \text { if } & \left(l_{o}, e_{o}\right)=(\underline{x}, \bar{x}) \\
\underline{w}[m-(1+\Delta) \tilde{g}] /(1+\Delta)+\tilde{G} & \text { if } & \left(l_{o}, e_{o}\right)=(\bar{x}, \underline{x}) \\
\bar{w}[m-(1+\Delta) \tilde{g}]+\tilde{G}, & \text { if } & \left(l_{o}, e_{o}\right)=(\bar{x}, \bar{x})
\end{array}\right.
$$

where $\tilde{g}=g^{l}+\rho\left(g^{h}-g^{l}\right)$ and $\tilde{G}=G^{l}+\rho\left(G^{h}-G^{l}\right)$. As a starting point, note that it is not necessary to consider $\left(l_{o}, e_{o}\right)=(\bar{x}, \underline{x})$ as a potential equilibrium outcome because $\mathbf{E}_{o}(\bar{x}, \underline{x})$ is strictly less than $\mathbf{E}_{o}(\underline{x}, \underline{x}), \mathbf{E}_{o}(\underline{x}, \bar{x})$ and $\mathbf{E}_{o}(\bar{x}, \bar{x})$ for all possible parameter values.

The action $\left(l_{o}, e_{o}\right)=(\bar{x}, \bar{x})$ will be an equilibrium if and only if $\mathbf{E}_{o}(\bar{x}, \bar{x})>\mathbf{E}_{o}(\underline{x}, \bar{x})$ and $\mathbf{E}_{o}(\bar{x}, \bar{x})>\mathbf{E}_{o}(\underline{x}, \underline{x})$. The critical value $\hat{\rho}$ [which is stated in the proposition] follows immediately after solving the former inequality for $\rho$, while the critical value $\hat{\omega}$ [which is stated in the proposition] follows immediately after solving the latter inequality for the ratio $\bar{w} / \underline{w}$.

The action $\left(l_{o}, e_{o}\right)=(\underline{x}, \bar{x})$ will be an equilibrium if and only if $\mathbf{E}_{o}(\bar{x}, \bar{x}) \leq \mathbf{E}_{o}(\underline{x}, \bar{x})$ and $\mathbf{E}_{o}(\underline{x}, \bar{x})>\mathbf{E}_{s}(\underline{x}, \underline{x})$. It is now readily checked that $(\underline{x}, \bar{x})$ will be optimal if and only if $\rho \geq \hat{\rho}$ and $\bar{w}>(1+\Delta) \underline{w}$. The proposition and its graphical portrayal in Figure 1 now follows immediately.

Proof of Result 2. Recall that if $f$ and $s$ reach an agreement $A \equiv\left\{\left(s_{f}^{h}, s_{s}^{h}\right) \mid s_{f}^{h}+s_{s}^{h} \geq g^{h}\right\}$ on how to share caregiving responsibilities, then the second-period utility for player $i(i=f, s)$ takes the linear form

$$
u_{i}^{h}=c_{i}\left(s_{i}^{h}\right)+G^{h}
$$

where

$$
c_{i}\left(s_{i}^{h}\right)=w_{i}\left[m-s_{i}^{h}\left(1+\delta_{i}^{p}\right)\right] /\left(1+\delta_{i}^{e}\right) .
$$

If, on the other hand, $f$ and $s$ fail to reach an agreement and perpetually disagree over how to share the required amount of care $g^{h}$, then their payoffs are given by

$$
d_{f}^{h}=c_{f}(0) \quad \text { and } \quad d_{s}^{h}=c_{s}(0)
$$

where $c_{i}(0)(i=f, s)$ is as in equation (5), but with $s_{i}^{h}=0$. The Nash bargaining solution of the bargaining situation described in the text is the unique pair of caregiving shares, denoted $\left(\hat{s}_{f}^{h}, \hat{s}_{s}^{h}\right)$, that maximizes the Nash product 
$\left(u_{f}^{h}-d_{f}^{h}\right)\left(u_{s}^{h}-d_{s}^{h}\right)$ subject to $0 \leq s_{f}^{h} \leq g^{h}$ and $s_{s}^{h}=g^{h}-s_{f}^{h}$. Thus the Nash bargaining solution solves

$$
\max _{s_{f}^{h}, s_{s}^{h}}\left[G^{h}-s_{f}^{h}\left(\frac{w_{f}\left(1+\delta_{f}^{p}\right)}{1+\delta_{f}^{e}}\right)\right]\left[G^{h}-s_{s}^{h}\left(\frac{w_{s}\left(1+\delta_{s}^{p}\right)}{1+\delta_{s}^{e}}\right)\right]
$$

subject to $0 \leq s_{f}^{h} \leq g^{h}$ and $s_{s}^{h}=g^{h}-s_{f}^{h}$. After substituting $s_{s}^{h}=g^{h}-s_{f}^{h}$ into the above problem and maximizing the resulting expression with respect to $s_{f}^{h}$, one readily obtains the Nash bargained caregiving shares $\left(\hat{s}_{f}^{h}, \hat{s}_{s}^{h}\right)$ stated in the proposition.

Proof of Result 3. For the sake of simplicity, but without any loss of generality, we restrict the proof of this proposition to parameter values satisfying the following:

Assumption 4 Let $g^{l}<g^{h}<m /(2+\Delta)$.

Under this assumption, the equilibrium mobility decisions of an only child are as illustrated in Figure 1(b). Consider now the equilibrium mobility characteristics of children with a sibling. Fix arbitrary actions $\left(l_{f}, e_{f}\right)$ and $\left(l_{s}, e_{s}\right)$ chosen in period 1. The payoff to child $i(i=f, s)$ at the end of period 2 in each state $k$ (where $k=l$ or $k=h$ ) will be as in equations (4) and (5) in the main text. Given assumptions 3 and 4 , the care units provided by player $i$ $(i=f, s)$ in each state $k$ that our game form admits are given by ${ }^{28}$

$$
s_{i}^{k}=\left\{\begin{array}{ll}
g^{l} & \text { if } \quad k=l \\
\frac{g^{h}+\theta_{i}-\theta_{j}}{2} & \text { if } \quad k=h
\end{array} \quad(i \neq j)\right.
$$

where

$$
\theta_{i}=\left[\frac{G^{h}\left(1+\delta_{i}^{e}\right)}{w_{i}\left(1+\delta_{i}^{p}\right)}\right]
$$

In period 1, each player $i(i=f, s)$ maximizes expected utility $(1-\rho) u_{i}^{l}+\rho u_{i}^{h}$ by location choice $l_{i} \in[\underline{x}, \bar{x}]$ and employment choice $e_{i} \in\{\underline{x}, \bar{x}\}$. For explicitness, note that

$$
\mathbf{E}_{i}=\frac{w_{i}}{1+\delta_{i}^{e}}\left[m-\left(1+\delta_{i}^{p}\right)\left[s_{i}^{l}+\rho\left(s_{i}^{h}-s_{i}^{l}\right)\right]\right]+\left[G^{l}+\rho\left(G^{h}-G^{l}\right)\right]
$$

Also note that we have omitted the arguments of the choice variables for simplicity: $s_{i}^{l}=s_{i}^{l}\left(l_{i}, e_{i}\right), s_{i}^{h}=s_{i}^{h}\left(l_{i}, e_{i}\right)$, $w_{i}=w_{i}\left(e_{i}\right), \delta_{i}^{e}=\delta_{i}^{e}\left(l_{i}, e_{i}\right)$ and $\delta_{i}^{p}=\delta_{i}^{p}\left(l_{i}\right)$. After differentiating $\mathbf{E}_{i}$ with respect to $l_{i}$, it is readily checked that player $i$ will choose to locate at one extreme of the economy, that is, either at $\underline{x}$ or at $\bar{x}$. It thus follows immediately that each player has essentially four pure strategies, namely $l_{i}=\underline{x}$ or $l_{i}=\bar{x}$ combined with $e_{i}=\underline{x}$ or $e_{i}=\bar{x}$.

In period 1 , child $f$ moves first in choosing $\left(l_{f}, e_{f}\right)$ and child $s$ moves second in choosing $\left(l_{s}, e_{s}\right)$. In doing so, each child will choose her actions recognizing how her choice will interact with that of her sibling in determining the equilibrium negotiated caregiving shares in the second period. We now solve the location game in period 1 using the standard backwards induction procedure.

Suppose that player $f$ chooses $\left(l_{f}, e_{f}\right)=(\bar{x}, \bar{x})$ at the first stage of period 1. Player $s$ 's equilibrium negotiated caregiving shares in period 2 (when $k=h)$ from the four pure strategies $\left(l_{s}, e_{s}\right) \in\{(\bar{x}, \bar{x}),(\underline{x}, \underline{x}),(\underline{x}, \bar{x}),(\bar{x}, \underline{x})\}$ are:

$$
s_{y}^{h}\left(l_{s}, e_{s}\right)=\left\{\begin{array}{lll}
\frac{g^{h}}{2} & \text { if } & \left(l_{s}, e_{s}\right)=(\bar{x}, \bar{x}) \\
\hat{s}_{s}^{h, 1} & \text { if } & \left(l_{s}, e_{s}\right)=(\underline{x}, \underline{x}) \\
\hat{s}_{s}^{h, 2} & \text { if } & \left(l_{s}, e_{s}\right)=(\underline{x}, \bar{x}) \\
\hat{s}_{s}^{h, 3} & \text { if } & \left(l_{s}, e_{s}\right)=(\bar{x}, \underline{x})
\end{array}\right.
$$

where

$$
\hat{s}_{s}^{h, 1}=\min \left\{\left[\frac{g^{h}}{2}+\frac{G^{h}}{2 \underline{w}}-\frac{G^{h}}{2 \bar{w}(1+\Delta)}\right], g^{h}\right\}
$$

${ }^{28}$ As in the case of an only child, it is assumed that the gains from caring, $G^{l}$ and $G^{h}$, are sufficiently large so that it is beneficial to provide care for aged parents. 


$$
\begin{aligned}
& \hat{s}_{s}^{h, 2}=\min \left\{\left[\frac{g^{h}}{2}+\frac{G^{h}(1+\Delta)}{2 \bar{w}}-\frac{G^{h}}{2 \bar{w}(1+\Delta)}\right], g^{h}\right\} \\
& \hat{s}_{s}^{h, 3}=\min \left\{\left[\frac{g^{h}}{2}+\frac{G^{h}(1+\Delta)}{2 \underline{w}}-\frac{G^{h}}{2 \bar{w}(1+\Delta)}\right], g^{h}\right\}
\end{aligned}
$$

Notice that $s_{s}^{h, 3}>s_{s}^{h, 2} \gtreqless s_{s}^{h, 1}>\frac{g^{h}}{2}$. Child $s^{\prime}$ ' expected payoff from her four pure strategies are:

$$
\mathbf{E}_{s}=\left\{\begin{array}{lll}
\bar{w}\left[m-(1+\Delta)\left(g^{l}+\rho\left(0.5 g^{h}-g^{l}\right)\right)\right]+\tilde{G} & \text { if } \quad\left(l_{s}, e_{s}\right)=(\bar{x}, \bar{x}) \\
\underline{w}\left[m-\left(g^{l}+\rho\left(\hat{s}_{s}^{h, 1}-g^{l}\right)\right)\right]+\tilde{G} & \text { if } \quad\left(l_{s}, e_{s}\right)=(\underline{x}, \underline{x}) \\
\bar{w}\left[m-\left(g^{l}+\rho\left(\hat{s}_{s}^{h, 2}-g^{l}\right)\right)\right] /(1+\Delta)+\tilde{G} & \text { if } \quad\left(l_{s}, e_{s}\right)=(\underline{x}, \bar{x}) \\
\underline{w}\left[m-(1+\Delta)\left(g^{l}+\rho\left(\hat{s}_{s}^{h, 3}-g^{l}\right)\right)\right] /(1+\Delta)+\tilde{G} & \text { if } \quad\left(l_{s}, e_{s}\right)=(\bar{x}, \underline{x})
\end{array}\right.
$$

where $\tilde{G}=G^{l}+\rho\left(G^{h}-G^{l}\right)$. Under assumption 4 , we do not need to consider $\left(l_{s}, e_{s}\right)=(\underline{x}, \bar{x})$ as a potential equilibrium strategy of child $s$ since $\mathbf{E}_{s}(\bar{x}, \bar{x})>\mathbf{E}_{s}(\underline{x}, \bar{x})$. And furthermore, we do not need to consider $\left(l_{s}, e_{s}\right)=(\bar{x}, \underline{x})$ since $\mathbf{E}_{s}(\underline{x}, \underline{x})>\mathbf{E}_{s}(\bar{x}, \underline{x})$. To compare $s$ 's expected payoffs from $\left(l_{s}, e_{s}\right)=(\bar{x}, \bar{x})$ and $\left(l_{s}, e_{s}\right)=(\underline{x}, \underline{x})$, suppose that the parameter values are such that

$$
\hat{s}_{s}^{h, 1}=\min \left\{\left[\frac{g^{h}}{2}+\frac{G^{h}}{2 \underline{w}}-\frac{G^{h}}{2 \bar{w}(1+\Delta)}\right], g^{h}\right\}=g^{h} .
$$

Condition $(C)$ essentially implies that the parameter values are such that if one player (say $i$ ) chooses $\left(l_{i}, e_{i}\right)=(\bar{x}, \bar{x})$ and player $j$ chooses $\left(l_{j}, e_{j}\right)=(\underline{x}, \underline{x})$, then the Nash bargaining solution is a corner solution with child $j$, who lives and works at the parents' place of residence, providing all of the required amount of care. ${ }^{29}$ It is now straightforward to check that the action $\left(l_{s}, e_{s}\right)=(\underline{x}, \underline{x})$ will be a best response to $\left(l_{f}, e_{f}\right)=(\bar{x}, \bar{x})$ if and only if

$$
\frac{\bar{w}}{\underline{w}} \leq \frac{2\left[\left(m-g^{l}\right)-\rho\left(g^{h}-g^{l}\right)\right.}{2 m-(1+\Delta)\left[2 g^{l}+\rho\left(g^{h}-2 g^{l}\right)\right]} .
$$

The critical value $\tilde{\omega}$ [which is stated in the proposition] now follows immediately.

Now suppose that player $f$ chooses $\left(l_{f}, e_{f}\right)=(\underline{x}, \underline{x})$. Player $s$ 's equilibrium negotiated caregiving shares in period 2 (when $k=h$ ) from her four pure strategies are:

$$
s_{y}^{s}\left(l_{s}, e_{s}\right)=\left\{\begin{array}{lll}
\hat{s}_{s}^{h, a} & \text { if } & \left(l_{s}, e_{s}\right)=(\bar{x}, \bar{x}) \\
\frac{g^{h}}{2} & \text { if } & \left(l_{s}, e_{s}\right)=(\underline{x}, \underline{x}) \\
\hat{s}_{s}^{h, b} & \text { if } & \left(l_{s}, e_{s}\right)=(\underline{x}, \bar{x}) \\
\hat{s}_{s}^{h, c} & \text { if } & \left(l_{s}, e_{s}\right)=(\bar{x}, \underline{x})
\end{array}\right.
$$

where

$$
\begin{gathered}
\hat{s}_{s}^{h, a}=\max \left\{0,\left[\frac{g^{h}}{2}+\frac{G^{h}}{2 \bar{w}(1+\Delta)}-\frac{G^{h}}{2 \underline{w}}\right]\right\} \\
\hat{s}_{s}^{h, b}=\left[\frac{g^{h}}{2}+\frac{G^{h}(1+\Delta)}{2 \bar{w}}-\frac{G^{h}}{2 \underline{w}}\right] \\
\hat{s}_{s}^{h, c}=\min \left\{\left[\frac{g^{h}}{2}+\frac{G^{h}(1+\Delta)}{2 \underline{w}}-\frac{G^{h}}{2 \underline{w}}\right], g^{h}\right\}
\end{gathered}
$$

\footnotetext{
${ }^{29}$ It is straightforward, though somewhat tedious, to show that all our qualitative insights remain the same in the scenario where the parameter values are such that the Nash bargaining solution is an interior solution.
} 
Notice that $\hat{s}_{s}^{h, c}>\hat{s}_{s}^{h, b} \gtreqless \frac{g^{h}}{2}>\hat{s}_{s}^{h, a}$. Child $s$ 's expected payoff from her four pure strategies are:

$$
\mathbf{E}_{s}=\left\{\begin{array}{lll}
\bar{w}\left[m-(1+\Delta)\left(g^{l}+\rho\left(s_{s}^{h, a}-g^{l}\right)\right)\right]+\tilde{G} & \text { if } & \left(l_{s}, e_{s}\right)=(\bar{x}, \bar{x}) \\
\underline{w}\left[m-\left(g^{l}+\rho\left(0.5 g^{h}-g^{l}\right)\right)\right]+\tilde{G} & \text { if } & \left(l_{s}, e_{s}\right)=(\underline{x}, \underline{x}) \\
\bar{w}\left[m-\left(g^{l}+\rho\left(\hat{s}_{s}^{h, b}-g^{l}\right)\right)\right] /(1+\Delta)+\tilde{G} & \text { if } & \left(l_{s}, e_{s}\right)=(\underline{x}, \bar{x}) \\
\underline{w}\left[m-(1+\Delta)\left(g^{l}+\rho\left(\hat{s}_{s}^{h, c}-g^{l}\right)\right)\right] /(1+\Delta)+\tilde{G} & \text { if } & \left(l_{s}, e_{s}\right)=(\bar{x}, \underline{x})
\end{array}\right.
$$

where $\tilde{G}=G^{l}+\rho\left(G^{h}-G^{l}\right)$. Under assumption 4 , we do not need to consider $\left(l_{s}, e_{s}\right)=(\underline{x}, \bar{x})$ as a potential equilibrium strategy of child $s$ since $\mathbf{E}_{s}(\bar{x}, \bar{x})>\mathbf{E}_{s}(\underline{x}, \bar{x})$. And furthermore, we do not need to consider $\left(l_{s}, e_{s}\right)=(\bar{x}, \underline{x})$ since $\mathbf{E}_{s}(\underline{x}, \underline{x})>\mathbf{E}_{s}(\bar{x}, \underline{x})$. To compare $s$ 's expected payoffs from $\left(l_{s}, e_{s}\right)=(\bar{x}, \bar{x})$ and $\left(l_{s}, e_{s}\right)=(\underline{x}, \underline{x})$, notice that under condition (C) we have that

$$
\hat{s}_{s}^{h, a}=\max \left\{0,\left[\frac{g^{h}}{2}+\frac{G^{h}}{2 \bar{w}(1+\Delta)}-\frac{G^{h}}{2 \underline{w}}\right]\right\}=0 .
$$

It is now straightforward to check that the action $\left(l_{s}, e_{s}\right)=(\underline{x}, \underline{x})$ will be a best response to $\left(l_{f}, e_{f}\right)=(\underline{x}, \underline{x})$ if and only if

$$
\frac{\bar{w}}{\underline{w}}<\frac{2\left(m-g^{l}\right)-\rho\left(g^{h}-2 g^{l}\right)}{2\left[m-(1-\rho)(1+\Delta) g^{l}\right]} .
$$

The critical value $\check{\omega}$ [which is stated in the proposition] now follows immediately.

Having characterized player $s$ 's best responses in the second stage of period 1, we now turn attention to player $f$ 's actions in the first stage of period 1. Suppose first that the parameter values are such

$$
\frac{2\left(m-g^{l}\right)-\rho\left(g^{h}-2 g^{l}\right)}{2\left[m-(1-\rho)(1+\Delta) g^{l}\right]}<\frac{2\left[\left(m-g^{l}\right)-\rho\left(g^{h}-g^{l}\right)\right.}{2 m-(1+\Delta)\left[2 g^{l}+\rho\left(g^{h}-2 g^{l}\right)\right]}<\frac{\bar{w}}{\underline{w}} .
$$

Given this set of parameter values, our analysis above shows that child $s$ 's best response to both $\left(l_{f}, e_{f}\right)=(\bar{x}, \bar{x})$ and $\left(l_{f}, e_{f}\right)=(\underline{x}, \underline{x})$ is to play $\left(l_{s}, e_{s}\right)=(\bar{x}, \bar{x})$. Condition $(C)$ implies that child $f$ 's equilibrium negotiated caregiving shares in period 2 (when $k=h$ ) from the two pure strategies $\left(l_{f}, e_{f}\right) \in\{(\underline{x}, \underline{x}),(\bar{x}, \bar{x})\}$ would be $\hat{s}_{f}^{h}(\bar{x}, \bar{x})=\frac{g^{h}}{2}$ and $\hat{s}_{f}^{h}(\underline{x}, \underline{x})=g^{h}$. It thus follows that player $f$ 's expected payoffs are:

$$
\mathbf{E}_{f}=\left\{\begin{array}{lll}
\bar{w}\left[m-(1+\Delta)\left(g^{l}+\rho\left(0.5 g^{h}-g^{l}\right)\right)\right]+\tilde{G} & \text { if } & \left(l_{f}, e_{f}\right)=(\bar{x}, \bar{x}) \\
\underline{w}\left[m-\left(g^{l}+\rho\left(g^{h}-g^{l}\right)\right)\right]+\tilde{G} & \text { if } & \left(l_{f}, e_{f}\right)=(\underline{x}, \underline{x})
\end{array}\right.
$$

where $\tilde{G}=G^{l}+\rho\left(G^{h}-G^{l}\right)$. The action $\left(l_{f}, e_{f}\right)=(\underline{x}, \underline{x})$ will be an equilibrium if and only if

$$
\frac{\bar{w}}{\underline{w}} \leq \frac{2\left[\left(m-g^{l}\right)-\rho\left(g^{h}-g^{l}\right)\right]}{2 m-(1+\Delta)\left[2 g^{l}+\rho\left(g^{h}-2 g^{l}\right)\right]}
$$

However, given the parameter values under consideration [equation (34)], this is never the case. It thus follows immediately that when (34) holds, then player $f$ and player $s$ would choose $\left(l_{f}, e_{f}\right)=(\bar{x}, \bar{x})$ and $\left(l_{s}, e_{s}\right)=(\bar{x}, \bar{x})$ respectively. This establishes Regions $B(3)$ and $B(4)$ in the result.

Now suppose that the parameter values are such

$$
\frac{2\left(m-g^{l}\right)-\rho\left(g^{h}-2 g^{l}\right)}{2\left[m-(1-\rho)(1+\Delta) g^{l}\right]}<\frac{\bar{w}}{\underline{w}}<\frac{2\left[\left(m-g^{l}\right)-\rho\left(g^{h}-g^{l}\right)\right.}{2 m-(1+\Delta)\left[2 g^{l}+\rho\left(g^{h}-2 g^{l}\right)\right]}
$$

Given this set of parameter values, our analysis above shows that child $s$ 's best response to $\left(l_{f}, e_{f}\right)=(\bar{x}, \bar{x})$ is to play $\left(l_{s}, e_{s}\right)=(\underline{x}, \underline{x})$, while her best response to $\left(l_{f}, e_{f}\right)=(\underline{x}, \underline{x})$ is to play $\left(l_{s}, e_{s}\right)=(\bar{x}, \bar{x})$. Condition $(C)$ implies that player $f$ 's equilibrium negotiated caregiving shares in period 2 (when $k=h$ ) from the two pure strategies $\left(l_{f}, e_{f}\right) \in\{(\underline{x}, \underline{x}),(\bar{x}, \bar{x})\}$ would be $\hat{s}_{f}^{h}(\bar{x}, \bar{x})=0$ and $\hat{s}_{f}^{h}(\underline{x}, \underline{x})=g^{h}$ respectively. It thus follows that player $f$ 's expected payoffs are:

$$
\mathbf{E}_{f}=\left\{\begin{array}{lll}
\bar{w}\left[m-(1+\Delta)(1-\rho) g^{l}\right]+\tilde{G} & \text { if } & \left(l_{f}, e_{f}\right)=(\bar{x}, \bar{x}) \\
\underline{w}\left[m-\left(g^{l}+\rho\left(g^{h}-g^{l}\right)\right)\right]+\tilde{G} & \text { if } & \left(l_{f}, e_{f}\right)=(\underline{x}, \underline{x})
\end{array}\right.
$$


where $\tilde{G}=G^{l}+\rho\left(G^{h}-G^{l}\right)$. The action $\left(l_{f}, e_{f}\right)=(\underline{x}, \underline{x})$ will be an equilibrium if and only if

$$
\frac{\bar{w}}{\underline{w}} \leq \frac{\left(m-g^{l}\right)-\rho\left(g^{h}-g^{l}\right)}{m-(1+\Delta)(1-\rho) g^{l}}
$$

However, given the parameter values under consideration [equation (36)], this is never the case. It thus follows immediately that when (36) holds, then player $f$ would choose $\left(l_{f}, e_{f}\right)=(\bar{x}, \bar{x})$, and player $s$ would best respond to this strategy by choosing $\left(l_{s}, e_{s}\right)=(\underline{x}, \underline{x})$. This establishes part Region $B(2)$ in the result.

Finally suppose that the parameter values are such that

$$
\frac{\bar{w}}{\underline{w}}<\frac{2\left(m-g^{l}\right)-\rho\left(g^{h}-2 g^{l}\right)}{2\left[m-(1-\rho)(1+\Delta) g^{l}\right]}<\frac{2\left[\left(m-g^{l}\right)-\rho\left(g^{h}-g^{l}\right)\right.}{2 m-(1+\Delta)\left[2 g^{l}+\rho\left(g^{h}-2 g^{l}\right)\right]} .
$$

Given this set of parameter values, our analysis above implies that child $s$ 's best response to both $\left(l_{f}, e_{f}\right)=(\bar{x}, \bar{x})$ and $\left(l_{f}, e_{f}\right)=(\underline{x}, \underline{x})$ is to play $\left(l_{s}, e_{s}\right)=(\underline{x}, \underline{x})$. Condition $(C 1)$ implies that player $f$ 's equilibrium negotiated caregiving shares in period 2 (when $k=h$ ) from the two pure strategies $\left(l_{f}, e_{f}\right) \in\{(\underline{x}, \underline{x}),(\bar{x}, \bar{x})\}$ would be $s_{f}^{h}(\bar{x}, \bar{x})=0$ and $s_{f}^{h}(\underline{x}, \underline{x})=\frac{g^{h}}{2}$ respectively. It thus follows that player $f$ 's expected payoffs are:

$$
\mathbf{E}_{f}=\left\{\begin{array}{lll}
\bar{w}\left[m-(1+\Delta)(1-\rho) g^{l}\right]+\tilde{G} & \text { if } & \left(l_{f}, e_{f}\right)=(\bar{x}, \bar{x}) \\
\underline{w}\left[m-\left(g^{l}+\rho\left(0.5 g^{h}-g^{l}\right)\right)\right]+\tilde{G} & \text { if } & \left(l_{f}, e_{f}\right)=(\underline{x}, \underline{x})
\end{array}\right.
$$

where $\tilde{G}=G^{l}+\rho\left(G^{h}-G^{l}\right)$. The action $\left(l_{f}, e_{f}\right)=(\bar{x}, \bar{x})$ will be an equilibrium if and only if

$$
\frac{\bar{w}}{\underline{w}} \geq \frac{2\left(m-g^{l}\right)-\rho\left(g^{h}-2 g^{l}\right)}{2\left[m-(1+\Delta)(1-\rho) g^{l}\right]} .
$$

However, given the parameter values under consideration [equation (38)], this is never the case. It thus follows immediately that when (38) holds, then player $f$ would choose $\left(l_{f}, e_{f}\right)=(\underline{x}, \underline{x})$, and player $s$ would best respond to this strategy by also choosing $\left(l_{s}, e_{s}\right)=(\underline{x}, \underline{x})$. This establishes Region $B(1)$ in the result. 
Appendix B: DATA AND Empirics

Summary Statistics, by Child Type (Germany)

\begin{tabular}{|c|c|c|c|c|c|c|}
\hline & \multicolumn{2}{|c|}{ Only Children } & \multicolumn{2}{|c|}{ Firstborn } & \multicolumn{2}{|c|}{ Second born } \\
\hline & Mean & Std.Dev. & Mean & Std.Dev. & Mean & Std.Dev. \\
\hline \multicolumn{7}{|l|}{ CHILDREN's CHARACTERISTICS: } \\
\hline Age & 34.0 & 9.0 & 32.2 & 3.5 & 28.8 & 3.4 \\
\hline Female & 0.54 & & 0.60 & & 0.54 & \\
\hline Year of Birth & 1965.7 & 9.6 & 1967.4 & 3.7 & 1970.8 & 3.6 \\
\hline Foreigner & 0.06 & & 0.07 & & 0.07 & \\
\hline East Germany & 0.31 & & 0.16 & & 0.14 & \\
\hline Married & 0.36 & & 0.53 & & 0.32 & \\
\hline Dependent Children & 0.26 & & 0.45 & & 0.31 & \\
\hline Number of Children aged 14 & 0.37 & 0.69 & 0.72 & 0.89 & 0.44 & 0.75 \\
\hline Higher Education & 0.33 & & 0.46 & & 0.38 & \\
\hline \multicolumn{7}{|l|}{ PARENTS' CharaCteristics: } \\
\hline Age of Oldest Parent & 64.1 & 12.2 & 59.7 & 6.1 & 59.7 & 6.1 \\
\hline Mother is Single ${ }^{\dagger}$ & 0.34 & & 0.18 & & 0.18 & \\
\hline Parent(s) are Homeowner & 0.60 & & 0.74 & & 0.74 & \\
\hline \multicolumn{7}{|c|}{ Labor Market in Home Region } \\
\hline High Unemployment & 0.67 & & 0.63 & & 0.63 & \\
\hline Rural Area & 0.63 & & 0.68 & & 0.68 & \\
\hline Number of observations & \multicolumn{2}{|c|}{279} & \multicolumn{2}{|c|}{176} & \multicolumn{2}{|c|}{176} \\
\hline
\end{tabular}

${ }^{\dagger}$ Includes mother is single, divorced, separated or widowed. The table reports the means of the variables used in the analysis by child type. For non-binary variables, standard deviations are reported as well. 